\title{
Bulletin of Environmental Contamination and Toxicology A polydimethylsiloxane rod extraction-based method for the determination of pharmaceuticals and triclosan by liquid chromatography in water samples --Manuscript Draft--
}

\begin{tabular}{|c|c|c|}
\hline Manuscript Number: & \multicolumn{2}{|l|}{ BECT-D-19-00663R3 } \\
\hline Full Title: & \multicolumn{2}{|c|}{$\begin{array}{l}\text { A polydimethylsiloxane rod extraction-based method for the determination of } \\
\text { pharmaceuticals and triclosan by liquid chromatography in water samples }\end{array}$} \\
\hline Article Type: & \multicolumn{2}{|l|}{ Original Research } \\
\hline Keywords: & \multicolumn{2}{|c|}{$\begin{array}{l}\text { polydimethylsiloxane rod, pharmaceuticals, triclosan, high performance liquid } \\
\text { chromatography, UV-vis, microextraction techniques. }\end{array}$} \\
\hline Corresponding Author: & \multicolumn{2}{|l|}{$\begin{array}{l}\text { Victoria Salvadó } \\
\text { Universitat de Girona Facultat de Ciencies } \\
\text { SPAIN }\end{array}$} \\
\hline \multicolumn{3}{|l|}{$\begin{array}{l}\text { Corresponding Author Secondary } \\
\text { Information: }\end{array}$} \\
\hline Corresponding Author's Institution: & \multicolumn{2}{|l|}{ Universitat de Girona Facultat de Ciencies } \\
\hline \multicolumn{3}{|l|}{$\begin{array}{l}\text { Corresponding Author's Secondary } \\
\text { Institution: }\end{array}$} \\
\hline First Author: & \multicolumn{2}{|l|}{ Maryam Mallek } \\
\hline \multicolumn{3}{|l|}{ First Author Secondary Information: } \\
\hline \multirow[t]{6}{*}{ Order of Authors: } & \multicolumn{2}{|l|}{ Maryam Mallek } \\
\hline & \multicolumn{2}{|l|}{ Mariem Chtourou } \\
\hline & \multicolumn{2}{|l|}{ Hèctor Monclús } \\
\hline & \multicolumn{2}{|l|}{ Khaled Walha } \\
\hline & \multicolumn{2}{|l|}{ Abdelhamid Ben Salah } \\
\hline & \multicolumn{2}{|l|}{ Victoria Salvadó } \\
\hline \multicolumn{3}{|c|}{ Order of Authors Secondary Information: } \\
\hline Funding Information: & $\begin{array}{l}\text { Horizon } 2020 \text { Framework Programme } \\
(689817)\end{array}$ & Dr. Victoria Salvadó \\
\hline Abstract: & \multicolumn{2}{|c|}{$\begin{array}{l}\text { A new analytical method for the determination of naproxen, ketoprofen, diclofenac, } \\
\text { carbamazepine, and triclosan in water samples by liquid chromatography is developed } \\
\text { and validated. The method is based on the extraction of the analytes by a } \\
\text { polydimethylsiloxane (PDMS) rod. The different parameters affecting extraction, such } \\
\text { as the addition of salt, pH, initial volume, extraction and elution times and elution } \\
\text { solvent, as well as the application of sonication, are studied. The results showed that } \\
\text { the detection limits are all in the } 0.1-0.3 \mu \mathrm{gL}-1 \text { range except for carbamazepine (6 } \\
\mu \mathrm{L}-1 \text { ) with relative standard deviations in the range of } 0.4-9.7 \% \text {. The method } \\
\text { developed, which was validated by analysing spiked surface water samples at } 10,25 \\
\text { and } 75 \mu \mathrm{L}-1 \text { gave recoveries of between } 84.8 \text { and } 111.2 \% \text {. In the case of } \\
\text { carbamazepine, a recovery of } 99.1 \% \text { was obtained at } 75 \mu \mathrm{g}-1 \text {. The main advantage } \\
\text { of the developed method is that allows high performance liquid chromatography- diode } \\
\text { array (HPLC-DAD), which is widely available in non-specialised laboratories, to be } \\
\text { applied for pharmaceuticals and triclosan determination in surface waters after } \\
\text { performing a preconcentration/clean-up step with PDMS rods as it has been shown by } \\
\text { analysing real water samples. }\end{array}$} \\
\hline
\end{tabular}


The original manuscript has been adapted including the associate editor comments in order to clarify some questions and to increase the quality of the manuscript. All changes in the manuscript have been highlighted in red. We express our gratitude to the reviewer for providing helpful comments and suggestions, which have clearly contributed to the improvement of our manuscript. We are confident that, after the recommended revision, the manuscript is now both clearer and more interesting, and we hope that the current revised version will meet the requirements to be accepted for publication in Bulletin of Environmetal Contamination and Toxicology (BECT).

1) Revise abstract and indicate recovery range (including carbamazepine) for all compounds at $10 \mathrm{ug} / \mathrm{L}$. The detection limits are misleading and must be revised. As it is written you are implying the method works for all compounds near the LOD. Change "real" to "spiked river". Discuss low recovery for carbamazepine including likely reasons for low recovery. Finally add a sentence explaining where this method may be used for environmental samples. Compare SPME detection limits to instrument detection limits and EF for each compound using HPLC -DAD.

The abstract has been revised and the recovery range has been given as requested, except for the case of CBZ. The reason for the low recovery of CBZ is that this compound is not well adsorb by the PDMS due to it is less apolar than the other compounds as is discussed on page 4 (lines 154-155). When all the method is applied the lowest CBZ concentration that can normally be detected is $6 \mathrm{ug} / \mathrm{L}$ and, hence, CBZ peak can be observed in the chromatogram at $10 \mathrm{ug} / \mathrm{L}$ (Fig. $6 \mathrm{~A}$ ). However, taking into account that the quantification limit for CBZ is $18 \mathrm{ug} / \mathrm{L}$, quantification was not performed. This is also the reason why the recovery of CBZ from the spiked river water samples was only calculated at the highest spiked level. Hence, you are right that the method does not work for all the compounds at the same level of sensitivity and this is now clearly explained in the manuscript. We have also revised the calculations of the LODs and LOQs for the other compounds included in the method by using the calibration data obtained at different days and by eliminating outliers resulting in an improvement of the values.

We have changed "real" to "spiked" as requested.

The reason why this method can be used for environmental samples are commented on pg. 11 (lines 314-324). Moreover, it is important to note that there are no regulations about the concentrations of these compounds in environmental waters so there are currently no requirements regarding the method detection limits.

SPME-HPLC-DAD detection limits as well as extraction efficiencies for these compounds are now included in Table 3 (pg. 8). As can be seen, the LODs reported for pharmaceuticals are higher than those obtained with our method, except for carbamazepine.

2) In the discussion, add a paragraph (line 322) describing the limitations of this 
method improvement over direction injection IDL, and include practical uses at concentrations $>20 \mathrm{ug} / \mathrm{L}$. What are likely interferences in environmental samples based on the river water sample? Explain the difficulty in resolving peaks using HPLC-DAD, and possible solutions to these issues. For example, can confidence in identification be improved by using matrix standards at several concentration levels?

We have introduced a sentence (pg. 11, lines 324-326) explaining the advantages of our method over direct injection that are clear in the case of all of the target compounds except CBZ, recognising that direct injection can be faster than our method depending on the type of clean-up method used to treat the environmental water samples.

Concentrations $>20 \mathrm{ug} / \mathrm{L}$ are not commonly found but, in any case, we can say that the advantage of the method presented here in these cases is, as before, that a separate clean-up step is avoided, although this comes at the cost of being a longer method, taking some 24 hours.

River water samples are representative samples of surface waters and can contain a wide variety of compounds that can interfere with the analysis such as suspended solids (humic and fulvic acids), other pollutants, etc. Peak resolution in HPLC-DAD can be improved by optimization of the chromatographic conditions through the composition of the mobile phase and the gradient as well as the mobile phase flux. In the proposed method these conditions were optimised using standard solutions containing the target compounds.

In the proposed methodology, the use of PDMS rods allows the performance of a clean-up and preconcentration step at the same time. The apolar characteristics of the PDMS rod avoid the adsorption of interfering polar compounds on the rod and the desorption with methanol prevents the desorption of the most apolar compounds, that are not soluble or poor soluble in methanol. Taking into account these aspects and as can be seen in the chromatogram of the spiked river water, the clean-up of the sample is very effective and no interferences are observed (Fig. 6A). It was surprising for us that after validating the method with spiked river water samples obtaining very good chromatograms (Fig. 6A), when the water sample from another river was analysed (Fig.6B), more peaks were observed in the chromatogram. This result is explained by the fact that other compounds with similar physical and chemical characteristics to the target analytes may be present in the sample. Hence, the use of matrix standards at several concentration levels can help to improve the method in the case of low resolved analyte peaks. Moreover, this problem can be also solved by optimizing the flux of the mobile phase and the gradient in order to improve the resolution of the peaks. 
The original manuscript has been adapted including the reviewer and the associate editor comments in order to clarify some questions and to increase the quality of the manuscript. All changes in the manuscript have been highlighted in red. We express our gratitude to the reviewers for providing helpful comments and suggestions, which have clearly contributed to the improvement of our manuscript. We are confident that, after the recommended revision, the manuscript is now both clearer and more interesting, and we hope that the current revised version will meet the requirements to be accepted for publication in Bulletin of Environmetal Contamination and Toxicology (BECT). $\mathrm{N}$ the

We have carefully revised all the experimental data and we found out that there was a mistake in the extraction conditions as all the data reported was obtained at $\mathrm{pH} 2$. Hence, this figure has been changed thorough all the manuscript. We apologize for this error.

Reviewer \#1: This is a revised manuscript regarding the extraction and HPLC analysis of various commonly used NSAIDs which make their ways to drinking water via river waters and lakes. Measuring NSAIDs in drinking water is an environmentally significant problem as it relates to animal and human health. Authors have answered several comments posted earlier, but my enthusiasm for this revised manuscript is still not improved due to not having used an internal standard as a marker of extraction efficiency and characterization of tiny peaks by LC-MS/MS or other mass spectrometric methods.

The adsorption efficiency was evaluated by determining the concentrations of the analytes in the solution after equilibrium was reached by LC-DAD analysis using a calibration curve in ultrapure water. When the desorption conditions were studied, a calibration curve in methanol was used. So, since the full sample treatment step consisted of adsoption by the PDMS rod followed by methanol desorption, analyte solutions in ultrapure water were used and the final concentrations of these analytes in the desorption solution were determined using a calibration curve in methanol media.

In order to evaluate the matrix effect and the accuracy of the method, spiked river water samples were analysed and the results were interpolated in a calibration curve obtained by applying the full procedure to the standard solutions. The calibration curve data is included in Table 1. This means that PDMS rods were immersed in the river water samples and the aqueous standard solutions, in which the optimum amount of salt was added and the $\mathrm{pH}$ was adjusted. The solutions were then agitated until equilibrium and, finally, they were desorbed in methanol. It is important to take into account that this sample treatment allows both the preconcentration of the analytes and the clean-up of the samples. Only peaks of the analytes were obtained in the chromatogram with these solutions.

On the other hand, in the case of the analysis of river water samples, more peaks were found but they were not analysed since our objective was to determine the target analytes in the samples not to characterize the whole sample composition. The identification of the analytes in river water samples was made by the retention time that was monitored at three wavelengths and the quantification by interpolating the peak area in the calibration curve in accordance with previous calibrations. We agree with 
the reviewer that the use of an MS detector would allow quantification and identification of the analytes. However, the purchase and maintenance costs of the HPLC-MS/MS instrumentation makes it unviable for routine laboratories, hence the development of preconcentration methods allowing HPLC-DAD for use in the determination of pharmaceuticals and antibacterial compounds is of great concern. Moreover, even when the most sensitive MS detection is used, the application of a cleanup/preconcentration step is required prior to chromatographic analysis, taking into account matrix effects on the ionization source. As is commented in the manuscript, the developed preconcentration method can be also used with HPLC-MS/MS.

The chromatogram coming out from HPLC-DAD may not reveal the target molecule(s) due to complexity of metrics and other contaminants present in the samples unless identified by mass spectrometric detector. Moreover, authors responded on page 3 , as "The chromatographic method was previously validated (data not shown)" is not acceptable. This should be supported either by the proper citation or method details.

As has been explained above, the retention time was used to identify whether or not the analyte is present in the river water sample. The sentence "the chromatographic method...." referred to instrumental chromatographic method which details are explained in lines 107-114 and the detection limits in lines 130-132. I would like to remark that these detection limits were considerable improved using the developed method (see Table 1).

Associate Editor: I believe that the novelty of the extraction method provides some merit for publication. However, several sections must revised. Make sure all abbreviations, including "SR", are defined in the text.

We have change SR (silicone rod) for polydimethylsiloxane (PDMS) rod and the rest of abbreviations are now defined thoroughly the manuscript as requested.

\section{Line 60: Provide equation for calculation of extraction efficiency;}

We have now included in the text a sentence (lines 150-152) explaining how extraction efficiency was calculated but given that its simplicity we didn't add any equation.

Extraction efficiency $=\left(m_{s}\right.$ mass of the analyte in the PDMS rod $) /\left(m_{0}\right.$ initial mass of the analyte in the solution) $\times 100$

- $\mathbf{m}_{\mathbf{s}}$ mass of the analyte in the PDMS rod $=\mathrm{V}$ (volum of solution) $\mathrm{x} \mathrm{C}_{0}$ (initial concentration) $-\mathrm{Vx}_{\mathrm{eq}}$ ( remaining analyte concentration at the equilibrium)

- $\mathbf{m}_{0}$ initial mass of the analyte in the solution $=\mathrm{V}$ (volum of solution) $\mathrm{xC}_{0}$ (initial concentration).

Line 120 - Provide on-column instrument detection limits of HPLC method and final method of calibration. Were calibration standards extracted from water? 
We have provided the instrumental detection limits in lines 131-133 and those of the final method in Table 1. The calibrations standards were prepared in ultrapure water as is made clear in lines 254-255.

\section{Line 129 - what additional sample types were evaluated?}

Only river water was evaluated.

\section{Line 141 - What is the minimum tolerance for extraction efficiency?}

Since extraction efficiency is calculated as the ratio between the mass of the analyte in the PDMS rod $\left(m_{s}\right)$ and the initial mass of the analyte in the solution $\left(m_{0}\right)$ as it has been explained above. These values are calculated through the determination of the analyte concentration in the aqueous phase at the equilibrium. The minimum tolerance is related to the detection limit of the instrumental calibration method.

\section{Should carbamazepine be dropped from the method?}

In fact, carbamazepine was not preconcentrated by PDMS rods given its polar characteristics.

Figure 6 - suggest including extracted standard and spiked sample at $10 \mathrm{ug} / \mathrm{L}$ instead of $100 \mathrm{ug} / \mathrm{L}$. Add representative chromatogram for spiked treated wastewater at same concentration.

We have now opted to include the chromatogram of a spiked river water sample at 10 $\mathrm{ug} / \mathrm{L}$ rather than the standard sample at $100 \mathrm{ug} / \mathrm{L}$. Unfortunately, the journal's space requirements don't allow us to include both. The peak corresponding to Carbamazepine can also be observed.

The reason LC-MS-MS is used for these is that concentrations are typically at sub-ppb levels, even in wastewater. Provide some justification in the abstract, introduction and conclusions of the need for a SR- HPLC-DAD method. Where and how can this method be used as described?

The preconcentration/clean-up method that we propose result in detection limits being lowered to sub-ppb levels for the most hydrophobic compounds, permitting the use of an HPLC-DAD instrument after preconcentration, which is of course much more practical for monitoring laboratories. This is now made clear in the abstract (lines 2024), introduction (lines 74-79) and conclusions (319-323). Moreover, this PDMS-rodbased method can also be applied when a LC-MS-MS instrument will be used as a clean-up method. 
1 A polydimethylsiloxane rod extraction-based method for the determination of

\title{
pharmaceuticals and triclosan by liquid chromatography in water samples
}

Maryam Mallek ${ }^{\mathrm{a}, \mathrm{b}}$, Mariem Chtourou ${ }^{\mathrm{a}, \mathrm{b}}$, Hèctor Monclús ${ }^{\mathrm{c}}$, Abdelhamid ben Salah ${ }^{\mathrm{a}}$, Khaled Walha ${ }^{\mathrm{a}}$ and Victoria Salvadó $* \mathrm{~b}$

${ }^{a}$ Laboratory of Material Science and Environment, Faculty of Science, University of Sfax, Tunisia.

${ }^{b}$ Department of Chemistry, ${ }^{c}$ LEQUIA (Institute of the Environment), University of Girona, M. Aurèlia Capmany, 69, 17003 Girona, Spain.

\begin{abstract}
A new analytical method for the determination of naproxen, ketoprofen, diclofenac, carbamazepine, and triclosan in water samples by liquid chromatography is developed and validated. The method is based on the extraction of the analytes by a polydimethylsiloxane (PDMS) rod. The different parameters affecting extraction, such as the addition of salt, $\mathrm{pH}$, initial volume, extraction and elution times and elution solvent, as well as the application of sonication, are studied. The results showed that the detection limits are all in the 0.1-0.3 $\mu \mathrm{gL}^{-1}$ range except for carbamazepine $\left(6 \mu \mathrm{gL}^{-1}\right)$ with relative standard deviations in the range of $0.4-9.7 \%$. The method developed, which was validated by analysing spiked surface water samples at 10, 25 and $75 \mu \mathrm{gL}^{-1}$ gave recoveries of between 84.8 and $111.2 \%$. In the case of carbamazepine, a recovery of $99.1 \%$ was obtained at $75 \mu \mathrm{gL}^{-1}$. The main advantage of the developed method is that allows high performance liquid chromatography- diode array (HPLC-DAD), which is widely available in non-specialised laboratories, to be applied for pharmaceuticals and triclosan determination in surface waters after performing a preconcentration/clean-up step with PDMS rods as it has been shown by analysing real water samples.
\end{abstract}

Keywords: polydimethylsiloxane rod, pharmaceuticals, triclosan, high performance liquid chromatography, UV-vis, microextraction techniques. 
Pharmaceuticals and antibacterial compounds are classified as emerging contaminants as they are regarded as possible threats to the aquatic environment and human health ( $\mathrm{Bu}$ et al. 2013; Liu and Wong 2013). Although these compounds are normally not regulated, diclofenac has recently been included in the European Union watch list (Directive 2013/39/EU) and triclosan has been categorized as a high priority pollutant by the Environmental Protection Agency (EPA) in the aggregate risk assessment (Chen et al. 2013).

Due to their poor biodegradability, these contaminants are normally not eliminated in sewage treatment plants, and therefore are able to make their way into drinking water via river waters and lakes (Delgado et al. 2013; Gros et al. 2012). Anti-inflammatory drugs, such as diclofenac (DCF), naproxen (NAP) and ketoprofen (KET), have been detected in surface waters in concentrations of $10 \mu \mathrm{gL}^{-1}, 121 \mu \mathrm{gL}^{-1}$, and $102 \mu \mathrm{gL}^{-1}$, respectively (Yang et al. 2017). Triclosan (TCS) was the most commonly found antibacterial in surface water with concentrations of up to $24 \mu \mathrm{gL}^{-1}$ (Blair et al. 2013; Kasprzyk-Hordern et al. 2008).

Liquid chromatography with ultraviolet (UV-vis) and mass spectrometry (MS) detection are among the most important analytical methodologies to measure trace levels of pharmaceuticals and triclosan, although they require sample enrichment steps prior to chromatographic analysis (Richardson and Ternes 2014). The extraction of the analytes with solid-phase extraction (SPE) while having some advantages requires relatively large volumes of toxic solvents and is laborious and costly (Togunde et al. 2012). The use of solid-phase microextraction (SPME), in which the analytes are extracted by a polydimethylsiloxane (PDMS) fibre, has the disadvantages of the fragility of the fibre and the need for a special device when combined with high performance liquid chromatography (HPLC) (PłotkaWasylka et al. 2015). Stir-bar sorptive extraction (SBSE) consists of a magnetic bar covered by a thin layer of a sorptive phase, generally PDMS, and provides improved extraction efficiencies in comparison with SPME (He et al. 2014). Other stir extraction techniques are stir-rod-sorptive extraction, stir-cake-sorptive extraction (SCSE), and rotating disk sorptive extraction (RDSE) that share the same sorptive principle as SPME (Cárdenas and Lucena 2017). In recent years, new microextraction techniques such as bar adsorptive microextraction (BA $\mu \mathrm{E})$ (Neng et al. 2010; Almeida et al. 2017) and dynamic fabric phase sorptive extraction (DFPSE) have been applied in the determination of pharmaceuticals and triclosan (Lakade et al. 2016).

All these microextraction techniques have great potential, however, some of them requires of the synthesis of polymeric sorbent phases (Ahmad et al. 2017; Almeida et al. 2017). Hence, there is a need for less costly and simpler methods by combining efficient extraction/preconcentration techniques, using commercial sorbents, with chromatographic techniques such as HPLC-DAD, that is available in routine monitoring laboratories and that can determine the target analytes at low $\mu \mathrm{g} / \mathrm{L}$ concentration levels. The extraction efficiency of technical silicone sorbents such as PDMS rods, which were introduced by Popp et al. 2004, meets analytical requirements in terms of purity, inertness and thermal stability and were applied to extract pharmaceuticals (Paschke et al. 2007). Other advantages of PDMS rods are their greater flexibility and robustness, together with the fact that they can be discarded after a single use, eliminating problems of carryover (van Pinxteren et al. 2010). Moreover, PDMS rods can be used as sorptive materials in passive sampling (Seethapathy and Górecki 2012).

The objective of this study is to develop a new analytical method for the determination of NAP, KET, CBZ, DCF, and TCS based on their extraction and preconcentration by PDMS 
rods followed by liquid desorption and high performance liquid chromatography (HPLCDAD) analysis. The method is validated by analysing spiked surface water samples and applied to the determination of target compounds in river waters. The analytical parameters of the developed method are compared with those obtained with other micro-extraction based techniques.

\section{Methods and Materials}

Triclosan (5-chloro-2-(2,4-dichlorophenoxy) phenol), naproxen ((2S)-2-(6 methoxynaphthalen-2-yl)propanoic acid), ketoprofen (2-(3-Benzoylphenyl)propanoic acid), carbamazepine (benzobenzazepine-11-carboxamide), and sodium diclofenac (sodium;2-[2(2,6-dichloroanilino)phenyl]acetate) were purchased from Sigma-Aldrich (Germany). Working solutions of pharmaceuticals and triclosan ranging from 10 to $150 \mu \mathrm{gL}^{-1}$ were prepared with ultra-pure water by dilution of a $500 \mathrm{mgL}^{-1}$ stock methanol solution. Chromatographic grade acetonitrile (Fisher, USA), sodium chloride (Carlo Erba, Italy) and analytical grade anhydrous sodium acetate, acetic and hydrochloric acids (Sigma-Aldrich, Germany) were used. Ultrapure water with conductivity of $18.2 \mathrm{M} \Omega / \mathrm{cm}$ was obtained from a water purification system (Millipore, USA).

An Agilent 1200 series high performance liquid chromatography system equipped with two pumps and a DAD detector was used. The analytes were separated in a C18 Luna column (50 $\times 2 \mathrm{~mm}, 2.5 \mu \mathrm{m}$ ) (Phenomenex, USA) using a gradient of mobile phase: (A) $0.1 \%$ acetic acid and $4.7 \mathrm{mM}$ of sodium acetate in ultra-pure water, and (B) acetonitrile ( $0 \mathrm{~min}, 90 \% \mathrm{~A} ; 5 \mathrm{~min}$, $75 \% \mathrm{~A} ; 10 \mathrm{~min}, 65 \% \mathrm{~A} ; 15 \mathrm{~min}, 20 \% \mathrm{~A}$ ) at a flow rate of $0.3 \mathrm{mLmin}^{-1}$. The detection wavelength was set at $242 \mathrm{~nm}$ for CBZ, KET and TCS; $250 \mathrm{~nm}$ for NAP; and 280nm for DCF. Water samples were filtered with a $0.2 \mu \mathrm{m}$ nylon membrane (Supelco, USA) before injection.

Commercial $10 \mathrm{~mm}$ elastomer PDMS rods (approx. $0.037 \mathrm{~g}$ ) were cut from a flexible $2 \mathrm{~mm}$ diameter PDMS cord (Goodfellow, England). These were then cleaned and stored in methanol and, immediately prior to use, were dried with a lint-free tissue. The PDMS rod was immersed in $50 \mathrm{~mL}$ of a $100 \mu \mathrm{gL}^{-1}$ solution of all the compounds in ultrapure water and $15 \%$ $\mathrm{w} / \mathrm{v}$ of $\mathrm{NaCl}$. The $\mathrm{pH}$ was adjusted as required $(2,3$, and 6$)$ and the extraction was performed for different periods of time $(3,5,8,10$ and $24 \mathrm{~h})$. The experiments were performed three times using a ten-point magnetic shaker (MultiMix D, Ovan, Spain) at $200 \mathrm{rpm}$. After extraction, the PDMS rod was removed with clean tweezers and then dried with a lint-free tissue. The rod was then placed into a tapered glass insert containing $200 \mu \mathrm{L}$ of methanol allowing the desorption process to take place for times ranging from 15 to 45 minutes with and without sonication in an ultrasonic bath (J.P. Selecta, Spain). The PDMS rod was removed and $10 \mu \mathrm{L}$ of the extract were then injected into the liquid chromatograph. During the experiments performed to find out the best adsorption and desorption conditions, aliquots of the desorbed solution were measured by interpolation in a calibration curve obtained using standard solutions in methanol. The detection limits of the instrumental method were: 2.42 $\mu \mathrm{gL}^{-1}$ for KET, $3.65 \mu \mathrm{gL}^{-1}$ for NAP, $3.99 \mu \mathrm{gL}^{-1}$ for DCF, $4.48 \mu \mathrm{gL}^{-1}$ for CBZ, and $5.45 \mu \mathrm{gL}^{-1}$ for TCS.

Water samples were collected in $1 \mathrm{~L}$ amber glass bottles from the Onyar, Ter and Fluvià rivers (Girona, Spain). Samples were transported to the laboratory under refrigeration and then stored at $4^{\circ} \mathrm{C}$ before characterization by determining their conductivity, chemical oxygen demand and ionic composition. The samples were filtered using a $0.45 \mu \mathrm{m}$ nylon membrane 
(Supelco, USA). After filtration, one of the samples was spiked with KET, NAP, DCF, CBZ, and TCS at different concentration levels $\left(10,25,75 \mu \mathrm{gL}^{-1}\right)$ and recovery experiments were carried out in triplicate. The other samples were analysed with the developed method.

\section{Results and discussion}

A systematic study of several parameters was undertaken to find the best extraction and desorption conditions for the preconcentration of pharmaceuticals and triclosan.

Extraction time was evaluated with $50 \mathrm{~mL}$ of a $100 \mu \mathrm{gL}^{-1}$ solution containing $15 \% \mathrm{NaCl}$ and all the studied compounds at $\mathrm{pH} 3$. Five different extraction periods $(3,5,8,10$, and $24 \mathrm{~h})$ were studied by analysing the remaining concentrations in the aqueous solution. Equilibrium was reached at $10 \mathrm{~h}$ for all compounds. The extraction efficiency, calculated as the ratio between the amount of analyte extracted by the PDMS rod $\left(\mathrm{m}_{\mathrm{s}}\right)$ and its initial mass in the aqueous phase $\left(\mathrm{m}_{0}\right)$, followed the order CBZ $(6 \%)$, KET (17\%), NAP (19\%), DCF (56\%), and TCS $(75 \%)$, which corresponds to their hydrophobicity order $\left(\log K_{o w}\right)$ : CBZ(2.45) < KET (3.1) < NAP (3.12) < DCF(3.91)< TCS (4.7), showing that the PDMS has the greatest affinity to those compounds that have $\log \mathrm{K}_{\mathrm{ow}}>3$ (Prieto et al. 2010) and a very low affinity to CBZ, which is the compound with the lowest hydrophobicity $\left(\log \mathrm{K}_{\mathrm{ow}}=2.45\right)$.

The effect of $\mathrm{pH}$ on the extraction efficiency was studied at different $\mathrm{pH}$ values $(2,3$, and 6$)$ by immersing a $10 \mathrm{~mm}$ PDMS rod in $50 \mathrm{~mL}$ of $100 \mu \mathrm{gL}^{-1}$ solution of the target analytes for $10 \mathrm{~h}$. After equilibrium, the rod was exposed to $200 \mu \mathrm{L}$ of methanol for $30 \mathrm{~min}$. The best results in terms of the concentrations of the analytes in the desorption solution were obtained at $\mathrm{pH} 2$ for TCS and KET, and at $\mathrm{pH} 3$ for NAP whereas for CBZ and DCF, no significant differences were obtained between $\mathrm{pH} 2$ and 3 (Fig.1). Finally, $\mathrm{pH} 2$ was selected as a compromise, particularly taking into account the need to improve the preconcentration of KET. At this $\mathrm{pH}$, all the analytes were present in their non-ionized forms: $\mathrm{pH}<\mathrm{pK}_{\mathrm{a}}$ (DCF pKa 4.3, NAP $\mathrm{pK}_{\mathrm{a}}$ 4.15, KET $\mathrm{pK}_{\mathrm{a}}$ 4.45, TCS $\mathrm{pk}_{\mathrm{a}}$ 8.14, and CBZ $\mathrm{pK}_{\mathrm{a}}$ 13.9).



Fig. 1 Effect of $\mathrm{pH}$ on the extraction $(\mathrm{n}=3)$ Initial: $50 \mathrm{~mL}$ of $100 \mu \mathrm{gL}^{-1}$ of pharmaceuticals and triclosan and $15 \% \mathrm{NaCl}$. Desorption volume: $200 \mu \mathrm{L}$ and desorption time: $30 \mathrm{~min}$.

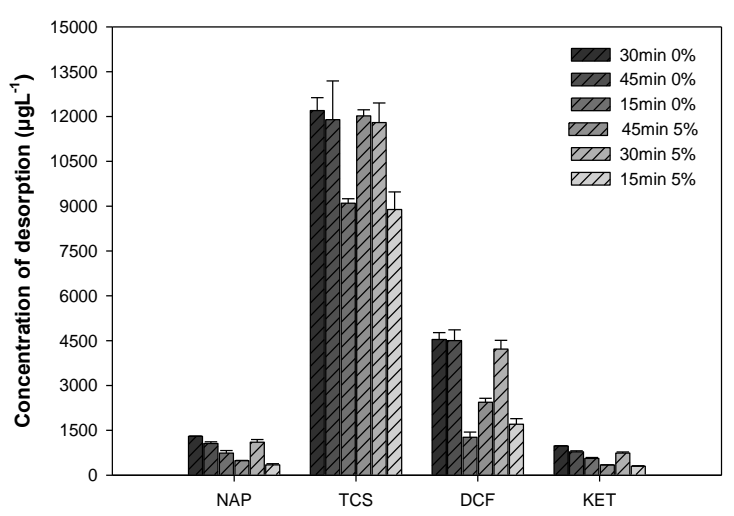

Fig. 2 Effect of the addition of methanol on the extraction $(n=3)$ and of the desorption time. 50 $\mathrm{mL}$ of $100 \mu \mathrm{gL}^{-1}$ of the target analytes at $\mathrm{pH} 2$ and $15 \% \mathrm{NaCl}$ with $5 \%$ of $\mathrm{MeOH}$ and without modifier. Desorption volume: $200 \mu \mathrm{L}$.

The addition of matrix modifiers such as methanol and $\mathrm{NaCl}$ to aqueous solutions is common in SBSE and SPME techniques. Here we study the addition of 5\% methanol to the sample, which is added to reduce the adsorption of organic analytes on the glassware (Valls-Cantenys 
et al. 2014) together with desorption time (15 $\mathrm{min}, 30 \mathrm{~min}$ and $45 \mathrm{~min}$ ). The concentrations in the desorption solutions increased without adding methanol (Fig. 2). With 5\% methanol, concentrations in the desorption solutions increased at $30 \mathrm{~min}$ and $45 \mathrm{~min}$, although less so than when no methanol was used, which consequently was the chosen option.

We also studied the salting-out effect (Valls-Cantenys et al. 2014) at concentrations of $\mathrm{NaCl}$ of $0,5,10$ and $15 \%(\mathrm{w} / \mathrm{v})$. The progressive addition of salt resulted in a significant increase in the extraction efficiency, which is seen in the increase in the concentrations of TCS, NAP, KET, DCF and CBZ in the desorption solution when the percentage of $\mathrm{NaCl}$ was increased to $15 \%$. (Fig. 3). Therefore, the addition of $15 \% \mathrm{NaCl}$ to the aqueous solution was found to be optimum for extracting the analytes.

The effect of the initial volume was tested by using volumes of 25,50 and $100 \mathrm{~mL}$, of a 20 $\mu \mathrm{gL}^{-1}$ solution containing all the analytes and $15 \% \mathrm{NaCl}$ at $\mathrm{pH} 2$. Analyte desorption was performed with $100 \mu \mathrm{L}$ of methanol in an ultrasonic bath for $30 \mathrm{~min}$. Results are presented as enrichment factors $(\mathrm{EF})$, defined as the ratio of analyte concentration $\left(\mathrm{C}_{\text {desor }}\right)$ in the desorbed methanol solution and the initial concentration in the aqueous phase $\left(\mathrm{C}_{0}\right)$ (Fig. 4). EF of 134 for TCS, 110 for DCF, 32 for NAP, 28 for KET and 2 for CBZ were obtained with a sample volume of $50 \mathrm{~mL}$ (Fig. 4). EF for TCS increased significantly as the sample volume was raised to $100 \mathrm{~mL}$, whereas the increase in DCF was relatively slight. EFs for KET and NAP remained almost unchanged with 25 and $50 \mathrm{~mL}$ and decreased with $100 \mathrm{~mL}$, while for CBZ the EF was only calculated for $50 \mathrm{~mL}$, which was the volume selected for the following experiments.

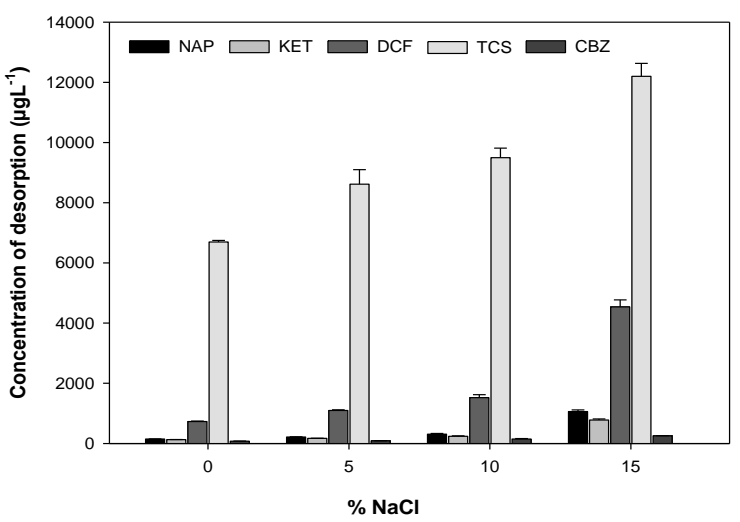

Fig.3 Effect of the addition of $\mathrm{NaCl}$ on the extraction $(\mathrm{n}=3) .50 \mathrm{~mL}$ of $100 \mu \mathrm{gL}^{-1}$ of pharmaceuticals and triclosan solution at $\mathrm{pH}=2$. Desorption volume: $200 \mu \mathrm{L}$; desorption time: $30 \mathrm{~min}$.

Methanol and acetonitrile were tested as desorption solvents to strip the target compounds

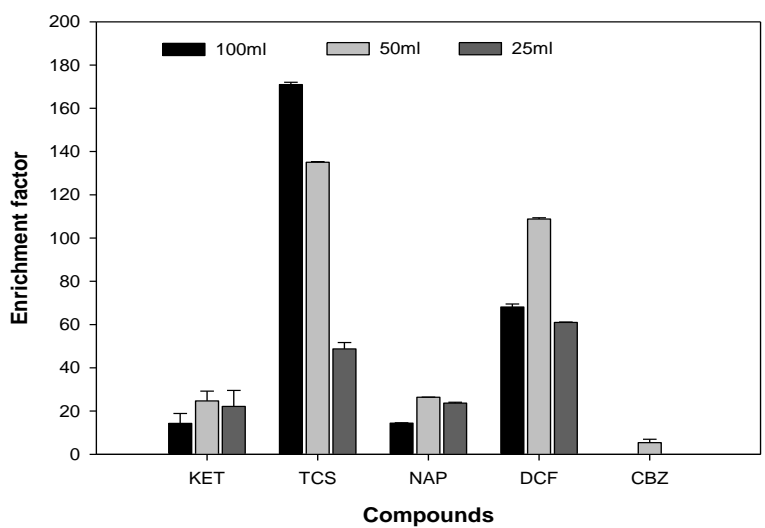

213 Fig.4 Enrichment factors obtained with 214 different sample volumes $(n=3)$. Initial 215 concentration: $20 \mu \mathrm{gL}^{-1}$ of pharmaceuticals and 216 triclosan at $\mathrm{pH} 2$ and $15 \% \mathrm{NaCl}$. Desorption 217 volume: $100 \mu \mathrm{L}$; desorption time: $30 \mathrm{~min}$. from the polymeric phase. Triplicate extractions were performed a $100 \mu \mathrm{gL}^{-1}$ solution in the previously described conditions. Then, three consecutive desorptions of $30 \mathrm{~min}$ each were performed and two solvent volumes of 100 and $200 \mu \mathrm{L}$ were tested. Acetonitrile is slightly better than methanol in desorbing TCS and DCF, which are the most lipophilic compounds, whereas no differences between methanol and acetonitrile were found for KET and NAP. 
Methanol (200 $\mu \mathrm{L})$ was finally selected as the desorption solvent, facilitating the chromatographic analysis.

After selecting the desorption solvent, the back-extraction time was also evaluated at different periods $(15,30$ and $45 \mathrm{~min})$. In order to accelerate the stripping of the adsorbed compounds, ultrasonic treatment was also tested, except in the case of $45 \mathrm{~min}$ where it was preferred to avoid the risk of breaking the vial. No significant difference was found between $30 \mathrm{~min}$ and 45 min with or without sonication for TCS, NAP and KET, whereas 15 min of sonication was only efficient in the case of DCF (Fig. 5). Given its greater simplicity, a desorption time of 30 min without sonication was selected.

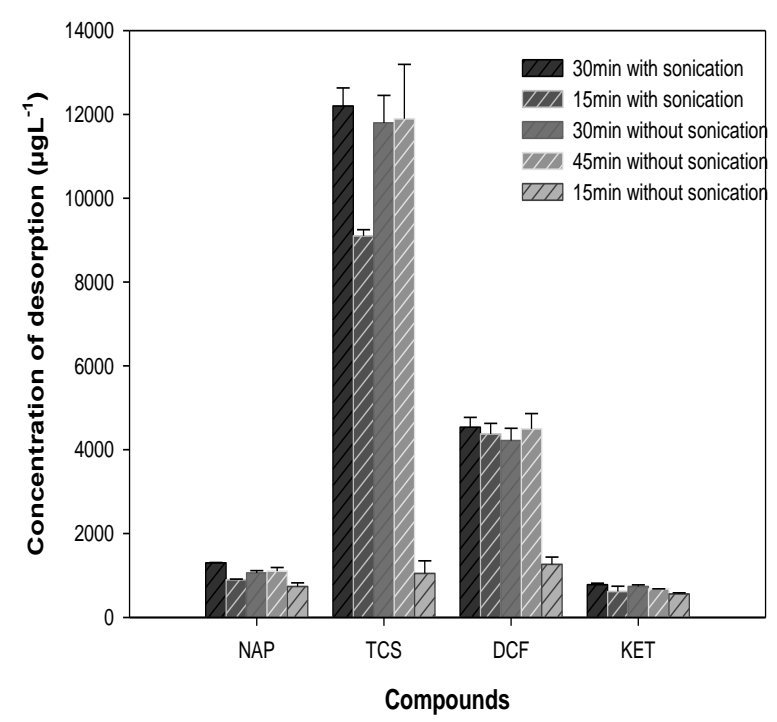

Fig. 5 Effect of desorption time and sonication on the desorption of the extracted pharmaceuticals and triclosan $(\mathrm{n}=3) .50 \mathrm{~mL}$ of $100 \mu \mathrm{gL}^{-1}$ solution of pharmaceuticals and triclosan at $\mathrm{pH}=2$ and $15 \% \mathrm{NaCl}$. Desorption volume: $200 \mu \mathrm{L}$.

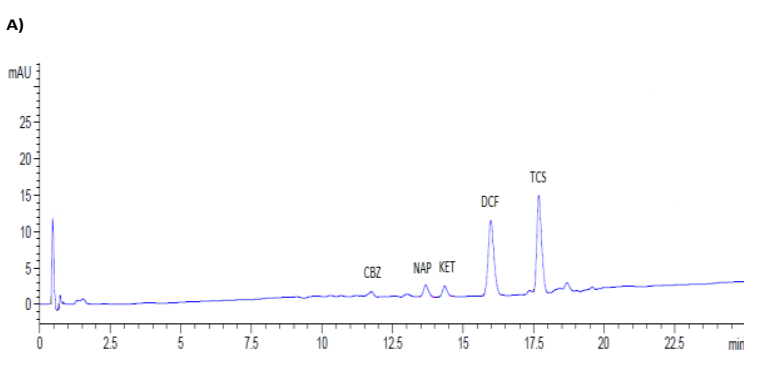

B)

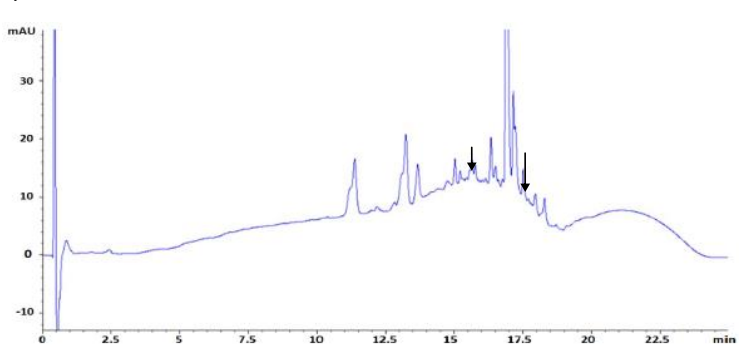

237

244 Fig. 6 A) Chromatogram of a river water 245 sample spiked at $10 \mu \mathrm{gL}^{-1}$ of pharmaceuticals 246 and triclosan, and B) Chromatogram of a river 247 water sample in which only DCF (15.5 min) 248 and TCS (17.5 min) were detected, obtained 249 with the PDMS-rod-HPLC-DAD method.

Linearity was evaluated by extracting ultrapure water samples spiked in triplicate with all the target compounds at five different concentration levels: 10, 25, 50, 75 and $100 \mu \mathrm{gL}^{-1}$. The concentrations were selected taking into account the different EFs obtained for each compound, since in the case of carbamazepine the EF was the lowest the calibration curve was built with standards ranging from 25 to $150 \mu \mathrm{gL}^{-1}$. The method was linear for all compounds and determination coefficients $\left(r^{2}\right)$ were higher than 0.990 (Table 1). The LODs and LOQs were calculated using the Excel regression analysis tool and considering a signalto-noise ratio of 3 and 10, respectively. LODs ranged from 0.1 to $0.3 \mu \mathrm{gL}^{-1}$, except for carbamazepine, which was $6.04 \mu \mathrm{gL}^{-1}$. LOQs ranged from 0.4 to $1.0 \mu \mathrm{gL}^{-1}$, except for carbamazepine, which was $18.33 \mu \mathrm{gL}^{-1}$. The precision of the method, expressed as RSD\%, was evaluated by replicate analysis $(n=6)$ of ultrapure water samples spiked at two concentration levels $\left(25\right.$ and $\left.100 \mu \mathrm{gL}^{-1}\right)$. Intraday precision was in the range of $0.4-9.7 \%$ at both levels and interday precision was between 3.8 and $10.5 \%$, except for carbamazepine, which was $18.8 \%$. 
Table 1 Calibration curves, LODs, LOQs and precision of the method.

\begin{tabular}{|c|c|c|c|c|c|c|c|c|c|}
\hline \multirow[t]{2}{*}{ Compounds } & \multirow{2}{*}{$\begin{array}{l}\text { Retention } \\
\text { time (min) }\end{array}$} & \multirow{2}{*}{$\begin{array}{c}\text { Equations of } \\
\text { calibration curve }\end{array}$} & \multirow{2}{*}{$\begin{array}{l}\text { Linearity } \\
\left(\mathrm{R}^{2}\right)\end{array}$} & \multicolumn{2}{|c|}{$\underset{(\mathrm{n}=6)}{\operatorname{RSD} \text { interday }(\%)}$} & \multicolumn{2}{|c|}{$\begin{array}{c}\text { RSD intraday }(\%) \\
(\mathrm{n}=2)\end{array}$} & \multirow{2}{*}{$\begin{array}{l}\text { LOD } \\
\left(\mu \mathrm{gL}^{-1}\right)\end{array}$} & \multirow{2}{*}{$\begin{array}{c}\mathbf{L O Q} \\
\left(\mu \mathrm{gL}^{-1}\right)\end{array}$} \\
\hline & & & & $25 \mu \mathrm{gL}^{-1}$ & $100 \mu \mathrm{gL}^{-1}$ & $25 \mu \mathrm{gL}^{-1}$ & $100 \mu \mathrm{gL}^{-1}$ & & \\
\hline KET & 13.8 & $y=9.9 x+1.5$ & 0.999 & 3.8 & 4.7 & 0.4 & 6.0 & 0.2 & 0.5 \\
\hline TCS & 17.5 & $y=29.1 x-1.2$ & 1 & 4.5 & 4.7 & 1.6 & 2.3 & 0.1 & 0.4 \\
\hline NAP & 13.3 & $y=3.4 x+1$ & 0.999 & 10.2 & 10.5 & 0.5 & 0.4 & 0.3 & 1.0 \\
\hline DCF & 15.5 & $\mathrm{y}=13.1 x+0.4$ & 0.999 & 5.9 & 5.6 & 5.8 & 2.2 & 0.2 & 0.7 \\
\hline CBZ & 11.12 & $y=0.5 x-1.7$ & 0.997 & 8 & 18.8 & 7.7 & 9.7 & 6.0 & 18.3 \\
\hline
\end{tabular}

268

269

270

271

272

273

274

275

276

277

278

279

280

281

To evaluate the applicability of the present methodology to real samples, assays were performed by analysing spiked river water samples at concentrations of 10,25 , and $75 \mu \mathrm{gL}^{-}$ ${ }^{1}$ of all the target compounds. However, CBZ's recoveries could only be calculated at the 75 $\mu \mathrm{gL}^{-1}$ as the spiking level of $25 \mu \mathrm{gL}^{-1}$ was too close to the LOQ. The recoveries obtained were in the range of $84.8-108.0 \%$ at the lowest concentration level, $87.3-111.2 \%$ for the medium concentration level, and $86.5-104 \%$ for the highest concentration level (Table 2). Before performing the recovery experiments, the river water samples were analysed by HPLC-MS/MS in order to ensure that the target compounds were not present. As can be seen in the chromatogram of the river water sample spiked at $10 \mu \mathrm{gL}^{-1}$ (Fig. $6 \mathrm{~A}$ ), the peaks of all the target analytes are separated between them and of the baseline. CBZ was not quantified as the peak area was below the corresponding to the LOQ.

Table 2 Recoveries (\%) of the target analytes by the developed methodology at three spiking levels

\begin{tabular}{lccc}
\multirow{2}{*}{ Compounds } & \multicolumn{3}{c}{ Concentration $\left(\mu \mathrm{gL}^{-1}\right)$} \\
\cline { 2 - 4 } CBZ & $\mathbf{1 0}$ & $\mathbf{2 5}$ & $\mathbf{7 5}$ \\
KET & - & - & $99.1 \pm 1.6$ \\
TCS & $97.7 \pm 5.6$ & $100.7 \pm 0.4$ & $96.1 \pm 3.8$ \\
NAP & $84.8 \pm 3.4$ & $87.3 \pm 7.1$ & $109.4 \pm 2.4$ \\
DCF & $91.2 \pm 2.6$ & $92.0 \pm 7.1$ & $86.5 \pm 1.1$ \\
& $108.0 \pm 7.5$ & $111.2 \pm 7.9$ & $104.0 \pm 8.1$
\end{tabular}

The developed method was compared with other microextraction techniques followed by HPLC-DAD analysis (Table 3). The proposed methodology had better recovery levels for KET, NAP, DCF and TCS than SBSE coated with PDMS (Silva and Nogueira 2008; Silva et al. 2008), polyurethane (PU) (Silva et al. 2008), and synthesized ionic liquids (IL) (Fan et al.

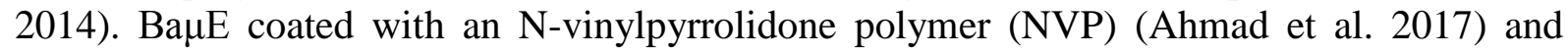
SPME with a PDMS/divynilbenzene (DVB) fibre (Vera-Candioti et al. 2008) gave better recoveries with the method developed here, except for CBZ. Similar recoveries were obtained 


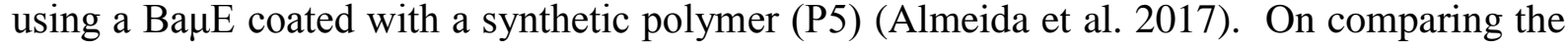
amount of the sorbent phases used and their chemical properties, it was found that smaller amounts such as those reported in Ahmad et al. 2017; Almeida et al. 2017; Silva and Nogueira 2008; Silva et al. 2008), led to lower recoveries being obtained, except in the case of

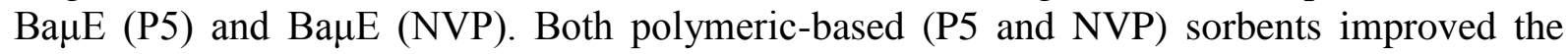
sensitivity and selectivity of HPLC-DAD determination given that a mixed hydrophobic and $\pi-\pi$ interaction is involved in the sorption process. The LODs achieved by the developed method are almost as good both in terms of order and number as those of other microextraction techniques used in combination with HPLC-DAD (Silva et al. 2008, VeraCandioti et al. 2008 ) and they can be improved by reducing the desorption volume. Another strategy to improve sensitivity is to combine the use of a commercial PDMS rod with LCMS/MS.

Table 3 Comparison of the LODs and average recovery of different static microextraction techniques for the determination of pharmaceuticals and triclosan

\begin{tabular}{|c|c|c|c|c|c|}
\hline Analytes & $\begin{array}{c}\text { Static micro-extraction } \\
\text { technique }\end{array}$ & $\begin{array}{c}\text { Recovery } \\
(\%)\end{array}$ & $\begin{array}{c}\text { LOD } \\
\left(\mu \mathrm{gL}^{-1}\right)\end{array}$ & $\begin{array}{l}\text { Amount } \\
\text { (g) or } \mu \mathrm{L}\end{array}$ & Ref. \\
\hline \multirow[t]{5}{*}{ NAP } & $\mathrm{BA} \mu \mathrm{E}(\mathrm{P} 5)$ & 100.1 & 0.025 & 0.001 & (Almeida et al. 2017) \\
\hline & SBSE (IL) & 52.7 & 0.31 & $30 \mu \mathrm{L}$ & (Fan et al. 2014) \\
\hline & $\begin{array}{l}\text { SBSE (PDMS) } \\
\text { SBSE (PU) }\end{array}$ & $\begin{array}{l}9.8 \\
78.3\end{array}$ & $\begin{array}{c}1 \\
0.4\end{array}$ & $\begin{array}{c}0.1201 \\
0.1\end{array}$ & $\begin{array}{l}\text { (Silva et al. 2008) } \\
\text { (Silva et al. 2008) }\end{array}$ \\
\hline & SPME (PDMS/DVB) & 117.9 & 0.5 & $65 \mu \mathrm{L}$ & (Vera-Candioti et al. 2008) \\
\hline & PDMS rod & 86.5 & 0.3 & 0.037 & Present study \\
\hline \multirow{4}{*}{ KET } & $\mathrm{BA} \mu \mathrm{E}(\mathrm{P} 5)$ & 101 & 0.05 & 0.001 & (Almeida et al. 2017) \\
\hline & SBSE (IL) & 51.6 & 0.27 & $30 \mu \mathrm{L}$ & (Fan et al. 2014) \\
\hline & SPME (PDMS/DVB) & 106.2 & 2.0 & $65 \mu \mathrm{L}$ & (Vera-Candioti et al. 2008) \\
\hline & PDMS rod & 96.1 & 0.2 & 0.037 & Present study \\
\hline \multirow[t]{6}{*}{ DCF } & $\mathrm{BA} \mu \mathrm{E}(\mathrm{P} 5)$ & 99.1 & 0.1 & 0.001 & (Almeida et al. 2017) \\
\hline & 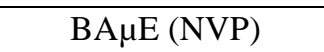 & 87.4 & 0.02 & 0.0025 & (Ahmad et al. 2017) \\
\hline & SBSE (PDMS) & 34.6 & 1.6 & 0.1201 & (Silva et al. 2008) \\
\hline & SBSE (PU) & 77.7 & 0.7 & 0.1 & (Silva et al. 2008) \\
\hline & SPME (PDMS/DVB) & 107.1 & 1.5 & $65 \mu \mathrm{L}$ & (Vera-Candioti et al. 2008) \\
\hline & PDMS rod & 104.0 & 0.2 & 0.037 & Present study \\
\hline \multirow{3}{*}{ CBZ } & $\mathrm{BA \mu E}(\mathrm{NVP})$ & 102.4 & 0.02 & 0.0025 & (Ahmad et al. 2017) \\
\hline & SPME (PDMS/DVB) & 79.4 & 3.0 & $65 \mu \mathrm{L}$ & (Vera-Candioti et al. 2008) \\
\hline & PDMS rod & 99.1 & 6.0 & 0.037 & Present study \\
\hline \multirow[t]{3}{*}{ TCS } & SBSE (PDMS) & 78.5 & 0.1 & 0.1201 & (Silva and Nogueira, 2008) \\
\hline & $\mathrm{BA \mu E}(\mathrm{NVP})$ & 74.5 & 0.03 & 0.0025 & (Ahmad et al. 2017) \\
\hline & PDMS rod & 109.4 & 0.1 & 0.037 & Present study \\
\hline
\end{tabular}


not carried out due to the poor resolution between the adjacent peaks (Fig.6 B). DCF at $\mu \mathrm{gL}^{-1}$ concentration levels have been detected in surface waters from different regions at mean concentration levels of $2.20 \mu \mathrm{gL}^{-1}$ and a maximum concentration of $18.74 \mu \mathrm{gL}^{-1}$ was found in the Llobregat river (Ginebreda et al. 2010) while in river water of South Africa was $9.69 \mu \mathrm{gL}^{-}$

${ }^{1}$ (Madikizela and Chimuka 2017).

The sensitive, effective and low-cost method, based on the combination of PDMS rod extraction with HPLC-DAD that has been developed here allows the determination of four pharmaceuticals (NAP, KET, CBZ, DCF) and TCS in surface water samples resulting in detection limits in the $0.1-0.3 \mu \mathrm{gL}^{-1}$ range, except $6.04 \mu \mathrm{gL}^{-1}$ for carbamazepine. These LODs are more than ten times lower that those obtained with the instrumental method, except for CBZ, and can be improved by using a lower volume of the desorption solvent which makes this method environmentally friendly. The main advantages of PDMS rods are that they are commercial and more economical than other sorbents, and are single use, so avoiding carryover and contamination issues and allowing HPLC-DAD, which is widely available in non-specialised laboratories, to be applied for pharmaceuticals and TCS determination in surface waters. It should, of course, be taken into account that there is a greater time requirement than for direct injection, although the later requires a clean-up step and it fails to achieve such a good level of sensitivity.

\section{Funding}

This study was funded by the by the European Union's Horizon 2020 research and innovation program under grant agreement No 689817.

\section{References}

Ahmad SM, Ide AH, Neng NR, Nogueira JMF (2017) Application of bar adsorptive microextraction to determine trace organic micro-pollutants in environmental water matrices. Inter J Environ Anal Chem 97:484-498. doi.org/10.1080/03067319.2017.1324024

Almeida C, Ahmad SM, Nogueira JMF (2017) Bar adsorptive microextraction technique application for the determination of pharmaceuticals in real matrices. Anal Bioanal Chem 409:2093-2106. doi.org/10.1007/s00216-016-0156-y

Blair BD, Crago JP, Hedman CJ, Klaper RD (2013) Pharmaceuticals and personal care products found in the Great Lakes above concentrations of environmental concern. Chemosphere 93:2116-2123. doi.org/10.1016/j.chemosphere.2013.07.057

Bu Q, Wang B, Huang J, Deng S, Yu G (2013) Pharmaceuticals and personal care products in the aquatic environment in China: A review. J Haz Mat 262:189-21. doi.org/10.1016/j.jhazmat.2013.08.040

Cárdenas S, Lucena R (2017) Recent Advances in Extraction and Stirring Integrated Techniques. Separations 4 (1): 6. doi.org/10.3390/separations4010006

Chen M-J, Liu Y-T, Lin C-W, Ponnusamy VK, Jen J-F (2013) Rapid determination of triclosan in personal care products using new in-tube based ultrasound-assisted salt-induced liquid-liquid microextraction coupled with high performance liquid chromatographyultraviolet detection. Anal Chim Acta 767:81-87. doi.org/10.1016/j.aca.2013.01.014 
Delgado A, Posada-Ureta O, Olivares M, Vallejo A, Etxebarria N (2013) Silicone rod extraction followed by liquid desorption-large volume injection-programmable temperature vaporiser-gas chromatography-mass spectrometry for trace analysis of priority organic pollutants in environmental water samples. Talanta 117:471-482. doi.org/10.1016/j.talanta.2013.09.028

Directive 2013/39/EU of the European Parliament and of the Council of 12 August 2013. Off, in: L226 (Ed.), J. Eur. Union L226, EU Water Framework 2013/39/UE Directive, pp. 1-17.

Fan W, Mao X, He M, Chen B, Hu B (2014) Development of novel sol-gel coatings by chemically bonded ionic liquids for stir bar sorptive extraction-application for the determination of NSAIDS in real samples. Anal Bioanal Chem 406:7261-7273. doi: 10.1007/s00216-014-8141-9

Ginebreda A, Muñoz I, de Alda ML, Brix R, López-Doval J, Barceló D (2010) Environmental risk assessment of pharmaceuticals in rivers: Relationships between hazard indexes and aquatic macroinvertebrate diversity indexes in the Llobregat River (NE Spain). Environ Inter 36:153-162. doi.org/10.1016/j.envint.2009.10.003

Gros M, Rodríguez-Mozaz S, Barceló D (2012) Fast and comprehensive multi-residue analysis of a broad range of human and veterinary pharmaceuticals and some of their metabolites in surface and treated waters by ultra-high-performance liquid chromatography coupled to quadrupole-linear ion trap tandem mass spectrometry. J Chromatogr A 1248:104121. doi.org/10.1016/j.chroma.2012.05.084

Kasprzyk-Hordern B, Dinsdale RM, Guwy AJ (2008) The occurrence of pharmaceuticals, personal care products, endocrine disruptors and illicit drugs in surface water in South Wales, UK. Wat Res 42:3498-3518. doi.org/10.1016/j.watres.2008.04.026

He M, Chen B, Hu B (2014) Recent developments in stir bar sorptive extraction, Anal Bioanal Chem 406: 2001-2026. DOI: 10.1007/s00216-013-7395-y

Lakade SS, Borrull F, Furton KG, Kabir A, Marcé RM, Fontanals N (2016) Dynamic fabric phase sorptive extraction for a group of pharmaceuticals and personal care products from environmental waters. J. Chromatogr. A 1456:19-26. doi.org/10.1016/j.chroma.2016.05.097

Liu J-L, Wong M-H (2013) Pharmaceuticals and personal care products (PPCPs): A review on environmental contamination in China. Environ Inter 59:208-224. doi.org/10.1016/j.envint.2013.06.012

Madikizela LM, Chimuka L (2017) Occurrence of naproxen, ibuprofen, and diclofenac residues in wastewater and river water of KwaZulu-Natal Province in South Africa. Environ Monit Assess 189:348. DOI 10.1007/s10661-017-6069-1

Neng NR, Silva ARM, Nogueira JMF (2010) Adsorptive micro-extraction techniques-Novel analytical tools for trace levels of polar solutes in aqueous media. J Chromatogr A 1217:73037310. doi.org/10.1016/j.chroma.2010.09.048

Paschke A, Brümmer J, Schürmann G (2007) Silicone rod extraction of pharmaceuticals from water. Anal Bioanal Chem 387:1417-1421.doi.org/10.1007/s00216-006-0986-0 
Płotka-Wasylka J, Szczepańska N, de la Guardia M, Namieśnik J (2015) Miniaturized solidphase extraction techniques. TrAC 73:19-38. DOI: 10.1016/j.trac.2015.04.026

Popp P, Bauer C, Paschke A, Montero L (2004) Application of a polysiloxane-based extraction method combined with column liquid chromatography to determine polycyclic aromatic hydrocarbons in environmental samples. Anal Chim Acta 504:307-312. doi.org/10.1016/j.aca.2003.10.040

Prieto A, Basauri O, Rodil R, Usobiaga A, Fernández LA, Etxebarria N, Zuloaga O (2010) Stir-bar sorptive extraction: A view on method optimisation, novel applications, limitations and potential solutions. J Chromatogr A 1217:2642-2666.

doi.org/10.1016/j.chroma.2009.12.051

Richardson SD, Ternes TA (2014) Water Analysis: Emerging Contaminants and Current Issues. Anal Chem 86:2813-2848. doi.org/10.1021/ac500508t

Seethapathy S, Górecki T (2012) Applications of polydimethylsiloxane in analytical chemistry: A review. Anal Chim Acta 750 48-62. DOI: 10.1016/j.aca.2012.05.004

Silva ARM, Nogueira JMF (2008) New approach on trace analysis of triclosan in personal care products, biological environmental matrices. Talanta 74:1498-1504. doi.org/10.1016/j.talanta.2007.09.040

Silva ARM, Portugal FCM, Nogueira JMF (2008) Advances in stir bar sorptive extraction for the determination of acidic pharmaceuticals in environmental water matrices: Comparison between polyurethane and polydimethylsiloxane polymeric phases. J Chromatogr A 1209:1016. doi.org/10.1016/j.chroma.2008.08.103

Togunde OP, Cudjoe E, Oakes KD, Mirnaghi FS, Servos MR, Pawliszyn J (2012) Determination of selected pharmaceutical residues in wastewater using an automated open bed solid phase microextraction system. J Chromatogr A 1262:34-42.

doi.org/10.1016/j.chroma.2012.09.011

Valls-Cantenys C, Iglesias M, Salvadó V (2014) Two polydimethylsiloxane rod extraction methods for the sensitive determination of phenolic compounds in water samples. J Sep Sci 37:3706-3713. doi.org/10.1002/jssc.201400823

van Pinxteren M, Paschke A, Popp P (2010) Silicone rod and silicone tube sorptive extraction. J. Chromatogr A 1217(16):2589-2598. doi.org/10.1016/j.chroma.2009.11.025

Vera-Candioti L, Gil García MD, Martínez Galera M, Goicoechea HC (2008) Chemometric assisted solid-phase microextraction for the determinationof anti-inflammatory and antiepileptic drugs in river water by liquid chromatography-diode array detection. J. Chromatogr A 1211:22-32. doi.org/10.1016/j.chroma.2008.09.093.

Yang Y, Ok YS, Kim K-H, Kwon EE, Tsang YF (2017) Occurrences and removal of pharmaceuticals and personal care products (PPCPs) in drinking water and water/sewage treatment plants: A review. Sci Tot Enviro. 596-597:303-320.

doi.org/10.1016/j.scitotenv.2017.04.102 
1 A polydimethylsiloxane rod extraction-based method for the determination of

\title{
pharmaceuticals and triclosan by liquid chromatography in water samples
}

Maryam Mallek ${ }^{\mathrm{a}, \mathrm{b}}$, Mariem Chtourou ${ }^{\mathrm{a}, \mathrm{b}}$, Hèctor Monclús ${ }^{\mathrm{c}}$, Abdelhamid ben Salah ${ }^{\mathrm{a}}$, Khaled Walha ${ }^{\mathrm{a}}$ and Victoria Salvadó $* \mathrm{~b}$

${ }^{a}$ Laboratory of Material Science and Environment, Faculty of Science, University of Sfax, Tunisia.

${ }^{\mathrm{b}}$ Department of Chemistry, ${ }^{\mathrm{c}}$ LEQUIA (Institute of the Environment), University of Girona, M. Aurèlia Capmany, 69, 17003 Girona, Spain.

\begin{abstract}
A new analytical method for the determination of naproxen, ketoprofen, diclofenac, carbamazepine, and triclosan in water samples by liquid chromatography is developed and validated. The method is based on the extraction of the analytes by a polydimethylsiloxane (PDMS) rod. The different parameters affecting extraction, such as the addition of salt, $\mathrm{pH}$, initial volume, extraction and elution times and elution solvent, as well as the application of sonication, are studied. The results showed that the detection limits are all in the 0.47 to 1.02 $\mu \mathrm{gL}^{-1}$ range except for carbamazepine $\left(3.4 \mu \mathrm{gL}^{-1}\right)$ with relative standard deviations in the range of $0.4-9.7 \%$. The method developed, which was validated by analysing spiked surface water samples at trace levels, gave recoveries of between 84.8 and $111.2 \%$. The main advantage of the developed method is that allows high performance liquid chromatographydiode array (HPLC-DAD), which is widely available in non-specialised laboratories, to be applied for pharmaceuticals and triclosan determination in surface waters after performing a preconcentration/clean-up step with PDMS rods as it has been shown by analysing real water samples.
\end{abstract}

Keywords: polydimethylsiloxane rod, pharmaceuticals, triclosan, high performance liquid chromatography, UV-vis, microextraction techniques. 


\section{Introduction}

Pharmaceuticals and antibacterial compounds are classified as emerging contaminants as they are regarded as possible threats to the aquatic environment and human health (Bu et al. 2013; Liu and Wong 2013). Although these compounds are normally not regulated, diclofenac has recently been included in the European Union watch list (Directive 2013/39/EU) and triclosan has been categorized as a high priority pollutant by the Environmental Protection Agency (EPA) in the aggregate risk assessment (Chen et al. 2013).

Due to their poor biodegradability, these contaminants are normally not eliminated in sewage treatment plants, and therefore are able to make their way into drinking water via river waters and lakes (Delgado et al. 2013; Gros et al. 2012). Anti-inflammatory drugs, such as diclofenac (DCF), naproxen (NAP) and ketoprofen (KET), have been detected in surface waters in concentrations of $10 \mu \mathrm{gL}^{-1}, 121 \mu \mathrm{gL}^{-1}$, and $102 \mu \mathrm{gL}^{-1}$, respectively (Yang et al. 2017). Triclosan (TCS) was the most commonly found antibacterial in surface water with concentrations of up to $24 \mu \mathrm{gL}^{-1}$ (Blair et al. 2013; Kasprzyk-Hordern et al. 2008).

Liquid chromatography with ultraviolet (UV-vis) and mass spectrometry (MS) detection are among the most important analytical methodologies to measure trace levels of pharmaceuticals and triclosan, although they require sample enrichment steps prior to chromatographic analysis (Richardson and Ternes 2014). The extraction of the analytes with solid-phase extraction (SPE) while having some advantages requires relatively large volumes of toxic solvents and is laborious and costly (Togunde et al. 2012). The use of solid-phase microextraction (SPME), in which the analytes are extracted by a polydimethylsiloxane (PDMS) fibre, has the disadvantages of the fragility of the fibre and the need for a special device when combined with high performance liquid chromatography (HPLC) (PłotkaWasylka et al. 2015). Stir-bar sorptive extraction (SBSE) consists of a magnetic bar covered by a thin layer of a sorptive phase, generally PDMS, and provides improved extraction efficiencies in comparison with SPME (He et al. 2014). Other stir extraction techniques are stir-rod-sorptive extraction, stir-cake-sorptive extraction (SCSE), and rotating disk sorptive extraction (RDSE) that share the same sorptive principle as SPME (Cárdenas and Lucena 2017). In recent years, new microextraction techniques such as bar adsorptive microextraction (BA $\mu \mathrm{E})($ Neng et al. 2010; Almeida et al. 2017) and dynamic fabric phase sorptive extraction (DFPSE) have been applied in the determination of pharmaceuticals and triclosan (Lakade et al. 2016).

All these microextraction techniques have great potential, however, some of them requires of the synthesis of polymeric sorbent phases (Ahmad et al. 2017; Almeida et al. 2017). Hence, there is a need for less costly and simpler methods by combining efficient extraction/preconcentration techniques, using commercial sorbents, with chromatographic techniques such as HPLC-DAD, that is available in routine monitoring laboratories and that can determine the target analytes at low $\mu \mathrm{g} / \mathrm{L}$ concentration levels. The extraction efficiency of technical silicone sorbents such as PDMS rods, which were introduced by Popp et al. 2004, meets analytical requirements in terms of purity, inertness and thermal stability and were applied to extract pharmaceuticals (Paschke et al. 2007). Other advantages of PDMS rods are their greater flexibility and robustness, together with the fact that they can be discarded after a single use, eliminating problems of carryover (van Pinxteren et al. 2010). Moreover, PDMS rods can be used as sorptive materials in passive sampling (Seethapathy and Górecki 2012). 
The objective of this study is to develop a new analytical method for the determination of NAP, KET, CBZ, DCF, and TCS based on their extraction and preconcentration by PDMS rods followed by liquid desorption and high performance liquid chromatography (HPLCDAD) analysis. The method is validated by analysing spiked surface water samples and applied to the determination of target compounds in river waters. The analytical parameters of the developed method are compared with those obtained with other micro-extraction based techniques.

\section{Methods and Materials}

Triclosan (5-chloro-2-(2,4-dichlorophenoxy) phenol), naproxen ((2S)-2-(6 methoxynaphthalen-2-yl)propanoic acid), ketoprofen (2-(3-Benzoylphenyl)propanoic acid), carbamazepine (benzobenzazepine-11-carboxamide), and sodium diclofenac (sodium;2-[2(2,6-dichloroanilino)phenyl]acetate) were purchased from Sigma-Aldrich (Germany). Working solutions of pharmaceuticals and triclosan ranging from 10 to $150 \mu \mathrm{gL}^{-1}$ were prepared with ultra-pure water by dilution of a $500 \mathrm{mgL}^{-1}$ stock methanol solution. Chromatographic grade acetonitrile (Fisher, USA), sodium chloride (Carlo Erba, Italy) and analytical grade anhydrous sodium acetate, acetic and hydrochloric acids (Sigma-Aldrich, Germany) were used. Ultrapure water with conductivity of $18.2 \mathrm{M} \Omega / \mathrm{cm}$ was obtained from a water purification system (Millipore, USA).

An Agilent 1200 series high performance liquid chromatography system equipped with two pumps and a DAD detector was used. The analytes were separated in a C18 Luna column (50 $\times 2 \mathrm{~mm}, 2.5 \mu \mathrm{m})($ Phenomenex, USA) using a gradient of mobile phase: (A) $0.1 \%$ acetic acid and $4.7 \mathrm{mM}$ of sodium acetate in ultra-pure water, and (B) acetonitrile ( $0 \mathrm{~min}, 90 \% \mathrm{~A} ; 5 \mathrm{~min}$, $75 \% \mathrm{~A} ; 10 \mathrm{~min}, 65 \% \mathrm{~A} ; 15 \mathrm{~min}, 20 \% \mathrm{~A}$ ) at a flow rate of $0.3 \mathrm{mLmin}^{-1}$. The detection wavelength was set at $242 \mathrm{~nm}$ for CBZ, KET and TCS; $250 \mathrm{~nm}$ for NAP; and 280nm for DCF. Water samples were filtered with a $0.2 \mu \mathrm{m}$ nylon membrane (Supelco, USA) before injection.

Commercial $10 \mathrm{~mm}$ elastomer PDMS rods (approx. $0.037 \mathrm{~g}$ ) were cut from a flexible $2 \mathrm{~mm}$ diameter PDMS cord (Goodfellow, England). These were then cleaned and stored in methanol and, immediately prior to use, were dried with a lint-free tissue. The PDMS rod was immersed in $50 \mathrm{~mL}$ of a $100 \mu \mathrm{gL}^{-1}$ solution of all the compounds in ultrapure water and $15 \%$ $\mathrm{w} / \mathrm{v}$ of $\mathrm{NaCl}$. The $\mathrm{pH}$ was adjusted as required $(2,3$, and 6$)$ and the extraction was performed for different periods of time $(3,5,8,10$ and $24 \mathrm{~h})$. The experiments were performed three times using a ten-point magnetic shaker (MultiMix D, Ovan, Spain) at $200 \mathrm{rpm}$. After extraction, the PDMS rod was removed with clean tweezers and then dried with a lint-free tissue. The rod was then placed into a tapered glass insert containing $200 \mu \mathrm{L}$ of methanol allowing the desorption process to take place for times ranging from 15 to 45 minutes with and without sonication in an ultrasonic bath (J.P. Selecta, Spain). The PDMS rod was removed and $10 \mu \mathrm{L}$ of the extract were then injected into the liquid chromatograph. During the experiments performed to find out the best adsorption and desorption conditions, aliquots of the desorbed solution were measured by interpolation in a calibration curve obtained using standard solutions in methanol. The detection limits of the instrumental method were: 2.42 $\mu \mathrm{gL}^{-1}$ for KET, $3.65 \mu \mathrm{gL}^{-1}$ for NAP, $3.99 \mu \mathrm{gL}^{-1}$ for DCF, $4.48 \mu \mathrm{gL}^{-1}$ for CBZ, and $5.45 \mu \mathrm{gL}^{-1}$ for TCS.

Water samples were collected in $1 \mathrm{~L}$ amber glass bottles from the Onyar, Ter and Fluvià rivers (Girona, Spain). Samples were transported to the laboratory under refrigeration and 
then stored at $4^{\circ} \mathrm{C}$ before characterization by determining their conductivity, chemical oxygen demand and ionic composition. The samples were filtered using a $0.45 \mu \mathrm{m}$ nylon membrane (Supelco, USA). After filtration, one of the samples was spiked with KET, NAP, DCF, CBZ, and TCS at different concentration levels $\left(10,25,75 \mu \mathrm{gL}^{-1}\right)$ and recovery experiments were carried out in triplicate. The other samples were analysed with the developed method.

\section{Results and discussion}

A systematic study of several parameters was undertaken to find the best extraction and desorption conditions for the preconcentration of pharmaceuticals and triclosan.

Extraction time was evaluated with $50 \mathrm{~mL}$ of a $100 \mu \mathrm{gL}^{-1}$ solution containing $15 \% \mathrm{NaCl}$ and all the studied compounds at $\mathrm{pH} 3$. Five different extraction periods $(3,5,8,10$, and $24 \mathrm{~h})$ were studied by analysing the remaining concentrations in the aqueous solution. Equilibrium was reached at $10 \mathrm{~h}$ for all compounds. The extraction efficiency, calculated as the ratio between the amount of analyte extracted by the PDMS rod $\left(\mathrm{m}_{\mathrm{s}}\right)$ and its initial mass in the aqueous phase $\left(\mathrm{m}_{0}\right)$, followed the order CBZ (6\%), KET (17\%), NAP (19\%), DCF (56\%), and TCS $(75 \%)$, which corresponds to their hydrophobicity order $\left(\log \mathrm{K}_{\text {ow }}\right)$ : $\operatorname{CBZ}(2.45)<\mathrm{KET}$ (3.1) < NAP (3.12) < DCF(3.91)< TCS (4.7), showing that the PDMS has the greatest affinity to those compounds that have $\log \mathrm{K}_{\mathrm{ow}}>3$ (Prieto et al. 2010).

The effect of $\mathrm{pH}$ on the extraction efficiency was studied at different $\mathrm{pH}$ values $(2,3$, and 6$)$ by immersing a $10 \mathrm{~mm}$ PDMS rod in $50 \mathrm{~mL}$ of $100 \mu \mathrm{gL}^{-1}$ solution of the target analytes for $10 \mathrm{~h}$. After equilibrium, the rod was exposed to $200 \mu \mathrm{L}$ of methanol for $30 \mathrm{~min}$. The best results in terms of the concentrations of the analytes in the desorption solution were obtained at $\mathrm{pH} 2$ for TCS and KET, and at $\mathrm{pH} 3$ for NAP whereas for CBZ and DCF, no significant differences were obtained between $\mathrm{pH} 2$ and 3 (Fig.1). Finally, $\mathrm{pH} 2$ was selected as a compromise, particularly taking into account the need to improve the preconcentration of KET. At this $\mathrm{pH}$, all the analytes were present in their non-ionized forms: $\mathrm{pH}<\mathrm{pK}_{\mathrm{a}}$ (DCF pKa 4.3, NAP $\mathrm{pK}_{\mathrm{a}} 4.15, \mathrm{KET}_{\mathrm{pK}}$ 4.45, TCS $\mathrm{pk}_{\mathrm{a}}$ 8.14, and CBZ $\mathrm{pK}_{\mathrm{a}}$ 13.9).

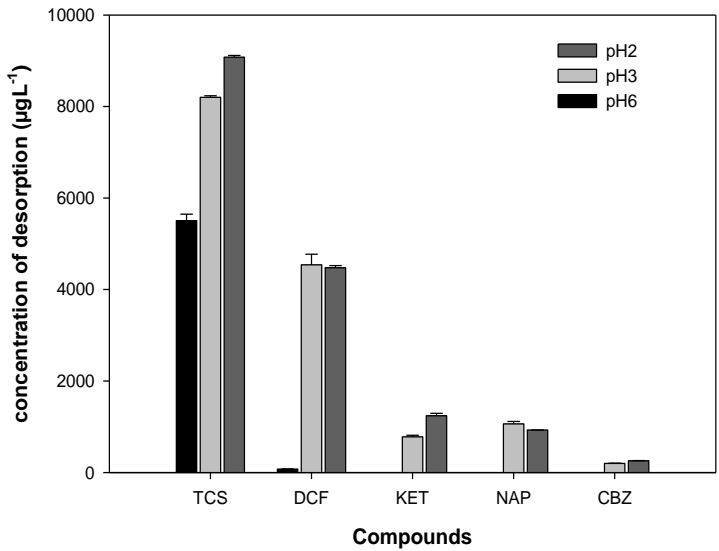

Fig. 1 Effect of $\mathrm{pH}$ on the extraction $(\mathrm{n}=3)$. Initial: $50 \mathrm{~mL}$ of $100 \mu \mathrm{gL}^{-1}$ of pharmaceuticals and triclosan and $15 \% \mathrm{NaCl}$. Desorption volume: $200 \mu \mathrm{L}$ and desorption time: $30 \mathrm{~min}$.

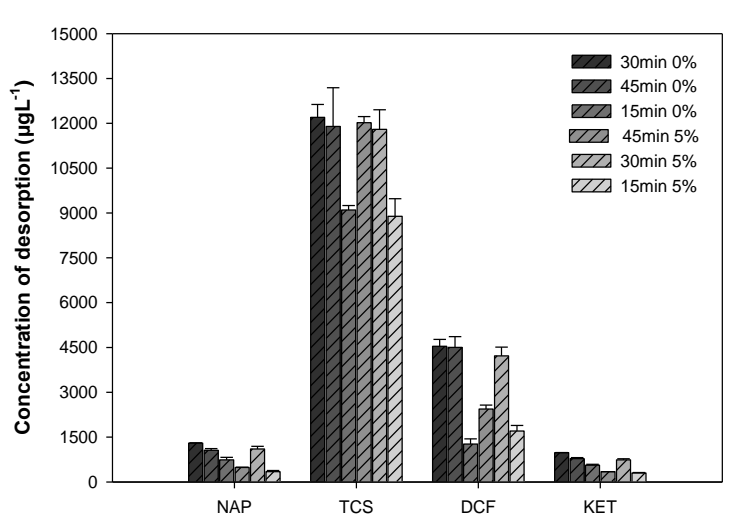

Fig. 2 Effect of the addition of methanol on the extraction $(n=3)$ and of the desorption time. 50 $\mathrm{mL}$ of $100 \mu \mathrm{gL}^{-1}$ of the target analytes at $\mathrm{pH} 2$ and $15 \% \mathrm{NaCl}$ with $5 \%$ of $\mathrm{MeOH}$ and without modifier. Desorption volume: $200 \mu \mathrm{L}$.

The addition of matrix modifiers such as methanol and $\mathrm{NaCl}$ to aqueous solutions is common in SBSE and SPME techniques. Here we study the addition of 5\% methanol to the sample, 
which is added to reduce the adsorption of organic analytes on the glassware (Valls-Cantenys et al. 2014) together with desorption time (15 min, $30 \mathrm{~min}$ and $45 \mathrm{~min}$ ). The concentrations in the desorption solutions increased without adding methanol (Fig. 2). With 5\% methanol, concentrations in the desorption solutions increased at $30 \mathrm{~min}$ and $45 \mathrm{~min}$, although less so than when no methanol was used, which consequently was the chosen option.

We also studied the salting-out effect (Valls-Cantenys et al. 2014) at concentrations of $\mathrm{NaCl}$ of $0,5,10$ and $15 \%(\mathrm{w} / \mathrm{v})$. The progressive addition of salt resulted in a significant increase in the extraction efficiency, which is seen in the increase in the concentrations of TCS, NAP, KET, DCF and CBZ in the desorption solution when the percentage of $\mathrm{NaCl}$ was increased to $15 \%$. (Fig. 3). Therefore, the addition of $15 \% \mathrm{NaCl}$ to the aqueous solution was found to be optimum for extracting the analytes.

The effect of the initial volume was tested by using volumes of 25,50 and $100 \mathrm{~mL}$, of a 20 $\mu \mathrm{gL}^{-1}$ solution containing all the analytes and $15 \% \mathrm{NaCl}$ at $\mathrm{pH} 2$. Analyte desorption was performed with $100 \mu \mathrm{L}$ of methanol in an ultrasonic bath for $30 \mathrm{~min}$. Results are presented as enrichment factors $(\mathrm{EF})$, defined as the ratio of analyte concentration $\left(\mathrm{C}_{\text {desor }}\right)$ in the desorbed methanol solution and the initial concentration in the aqueous phase $\left(\mathrm{C}_{0}\right)$ (Fig. 4).

EF for TCS increased significantly as the sample volume was raised to $100 \mathrm{~mL}$, whereas the increase in DCF was relatively slight. EFs for KET and NAP remained almost unchanged with 25 and $50 \mathrm{~mL}$ and decreased with $100 \mathrm{~mL}$, while for CBZ the EF was only calculated for $50 \mathrm{~mL}$ (Fig. 4). A $50 \mathrm{~mL}$ sample volume was selected for the following experiments.

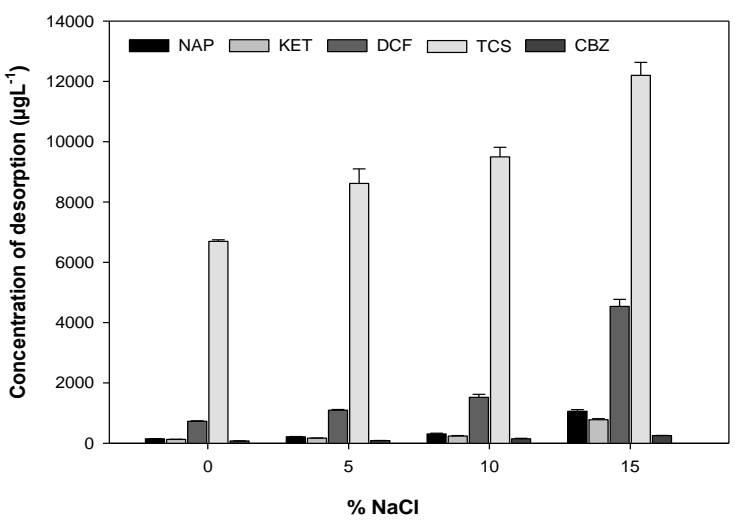

203
Fig.3 Effect of the addition of $\mathrm{NaCl}$ on the extraction $(\mathrm{n}=3) .50 \mathrm{~mL}$ of $100 \mu \mathrm{gL}^{-1}$ of pharmaceuticals and triclosan solution at $\mathrm{pH}=2$. Desorption volume: $200 \mu \mathrm{L}$; desorption time: $30 \mathrm{~min}$.

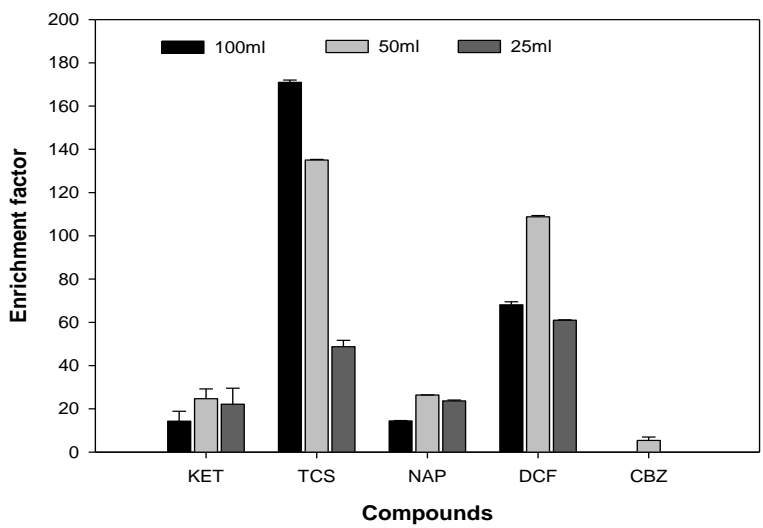

Fig.4 Enrichment factors obtained with different sample volumes $(n=3)$. Initial concentration: $20 \mu \mathrm{gL}^{-1}$ of pharmaceuticals and triclosan at $\mathrm{pH} 2$ and $15 \% \mathrm{NaCl}$. Desorption volume: $100 \mu \mathrm{L}$; desorption time: $30 \mathrm{~min}$.

Methanol and acetonitrile were tested as desorption solvents to strip the target compounds from the polymeric phase. Triplicate extractions were performed a $100 \mu \mathrm{gL}^{-1}$ solution in the previously described conditions. Then, three consecutive desorptions of $30 \mathrm{~min}$ each were performed and two solvent volumes of 100 and $200 \mu \mathrm{L}$ were tested. Acetonitrile is slightly better than methanol in desorbing TCS and DCF, which are the most lipophilic compounds, whereas no differences between methanol and acetonitrile were found for KET and NAP 
Methanol was finally selected as the desorption solvent, facilitating the chromatographic analysis.

After selecting the desorption solvent, the back-extraction time was also evaluated at different periods $(15,30$ and $45 \mathrm{~min})$. In order to accelerate the stripping of the adsorbed compounds, ultrasonic treatment was also tested, except in the case of 45 min where it was preferred to avoid the risk of breaking the vial. No significant difference was found between $30 \mathrm{~min}$ and 45 min with or without sonication for TCS, NAP and KET, whereas 15 min of sonication was only efficient in the case of DCF (Fig. 5). Given its greater simplicity, a desorption time of 30 min without sonication was selected.

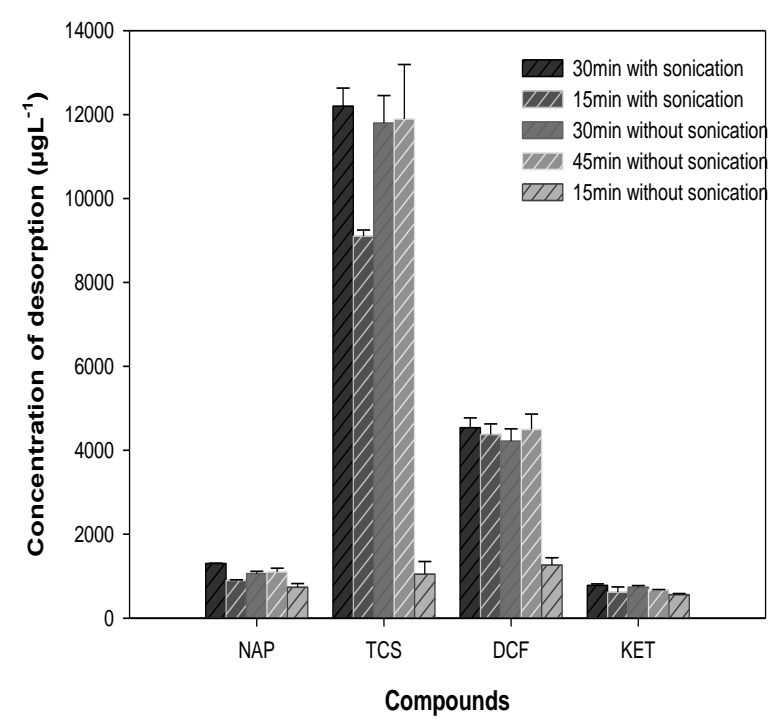

Fig. 5 Effect of desorption time and sonication on the desorption of the extracted pharmaceuticals and triclosan $(\mathrm{n}=3) .50 \mathrm{~mL}$ of $100 \mu \mathrm{gL}^{-1}$ solution of pharmaceuticals and triclosan at $\mathrm{pH}=2$ and $15 \% \mathrm{NaCl}$. Desorption volume: $200 \mu \mathrm{L}$.

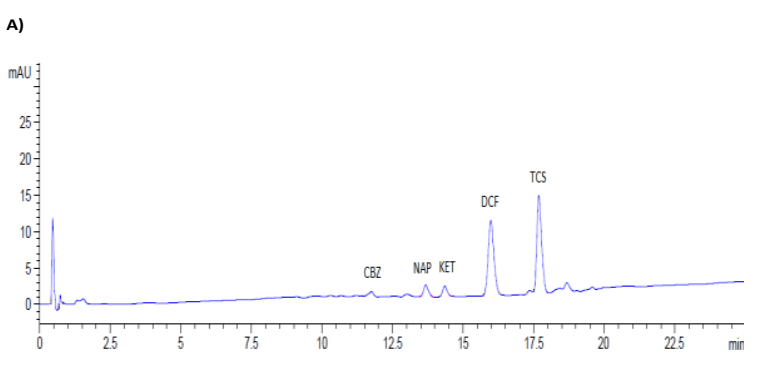

B)

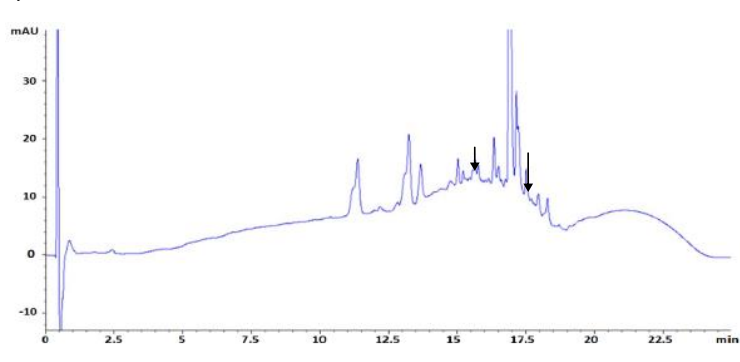

236

243 Fig. 6 A) Chromatogram of a river water 244 sample spiked at $10 \mu \mathrm{gL}^{-1}$ of pharmaceuticals 245 and triclosan, and B) Chromatogram of a river 246 water sample in which only DCF (15.5 min) 247 and TCS (17.5 min) were detected, obtained 248 with the PDMS-rod-HPLC-DAD method.

Linearity was evaluated by extracting ultrapure water samples spiked in triplicate with all the target compounds at five different concentration levels: 10, 25, 50, 75 and $100 \mu \mathrm{gL}^{-1}$. The concentrations were selected taking into account the different EFs obtained for each compound, since in the case of carbamazepine the EF is practically 1 where as in the case of triclosan, the most hydrophobic compound tested, the EF is 174.The method was linear for all compounds and determination coefficients $\left(r^{2}\right)$ were higher than 0.990 (Table 1). The LODs and LOQs were calculated using the Excel regression analysis tool and considering a signalto-noise ratio of 3 and 10 , respectively. LODs ranged from 0.47 to $1.02 \mu \mathrm{gL}^{-1}$, except for carbamazepine, which was $3.40 \mu \mathrm{gL}^{-1}$. LOQs ranged from 1.44 to $3.17 \mu \mathrm{gL}^{-1}$, except for carbamazepine, which was $10.33 \mu \mathrm{gL}^{-1}$. The precision of the method, expressed as RSD\%, was evaluated by replicate analysis $(n=6)$ of ultrapure water samples spiked at two concentration levels $\left(25\right.$ and $\left.100 \mu \mathrm{gL}^{-1}\right)$. Intraday precision was in the range of $0.4-9.7 \%$ at both levels and interday precision was between 3.8 and $10.5 \%$, except for carbamazepine, which was $18.8 \%$. 
Table 1 Calibration curves, LODs, LOQs and precision of the method.

\begin{tabular}{|c|c|c|c|c|c|c|c|c|c|}
\hline \multirow[t]{2}{*}{ Compounds } & \multirow{2}{*}{$\begin{array}{l}\text { Retention } \\
\text { time (min) }\end{array}$} & \multirow{2}{*}{$\begin{array}{c}\text { Equations of } \\
\text { calibration curve }\end{array}$} & \multirow{2}{*}{$\begin{array}{c}\text { Linearity } \\
\left(\mathrm{R}^{2}\right)\end{array}$} & \multicolumn{2}{|c|}{$\underset{(\mathrm{n}=6)}{\text { RSD interday }(\%)}$} & \multirow{2}{*}{\multicolumn{2}{|c|}{$\begin{array}{l}\text { RSD intraday (\%) } \\
(\mathrm{n}=2) \\
25 \mu \mathrm{gL}^{-1} \mathbf{1 0 0} \mu \mathrm{gL}^{-1}\end{array}$}} & \multirow{2}{*}{$\begin{array}{l}\text { LOD } \\
\left(\mu \mathrm{gL}^{-1}\right)\end{array}$} & \multirow{2}{*}{$\begin{array}{c}\text { LOQ } \\
\left(\mu \mathrm{gL}^{-1}\right)\end{array}$} \\
\hline & & & & $25 \mu \mathrm{gL}^{-1}$ & $100 \mu \mathrm{gL}^{-1}$ & & & & \\
\hline KET & 13.8 & $y=14.15 x-34.01$ & 0.999 & 3.8 & 4.7 & 0.4 & 6.0 & 1.02 & 3.17 \\
\hline TCS & 17.5 & $y=96.5 x-76.68$ & 1 & 4.5 & 4.7 & 1.6 & 2.3 & 0.47 & 1.44 \\
\hline NAP & 13.3 & $\begin{array}{l}\mathrm{y} \\
=7.538 x+13.41\end{array}$ & 0.999 & 10.2 & 10.5 & 0.5 & 0.4 & 0.56 & 1.70 \\
\hline DCF & 15.5 & $\begin{array}{l}\mathrm{y} \\
=38.62 x+88.79\end{array}$ & 0.999 & 5.9 & 5.6 & 5.8 & 2.2 & 0.75 & 2.24 \\
\hline CBZ & 11.12 & $y=2.094 x-54.82$ & 1 & 8 & 18.8 & 7.7 & 9.7 & 3.40 & 10.33 \\
\hline
\end{tabular}

To evaluate the applicability of the present methodology to real samples, assays were performed by analysing spiked river water samples at concentrations of 10,25 , and $75 \mu \mathrm{gL}^{-}$ ${ }^{1}$ of all the target compounds. The chromatogram of the river water sample spiked at $10 \mu \mathrm{gL}^{-1}$ is shown in Fig. 6 A. The recoveries obtained were in the range of $84.8-108.01 \%$ at the lowest concentration level, $87.31-111.18 \%$ for the medium concentration level, and 86.53$103.98 \%$ for the highest concentration level (Table 2). Before performing the recovery experiments, the river water samples were analysed by HPLC-MS/MS in order to ensure that the target compounds were not present.

Table 2 Recoveries (\%) of the target analytes by the developed methodology at three spiking levels

\begin{tabular}{lccc}
\multirow{2}{*}{ Compounds } & \multicolumn{3}{c}{ Concentration $\left(\mu \mathrm{gL}^{-1}\right)$} \\
\cline { 2 - 4 } CBZ & $\mathbf{1 0}$ & $\mathbf{2 5}$ & $\mathbf{7 5}$ \\
KET & - & - & $99.07 \pm 1.59$ \\
TCS & $97.66 \pm 5.65$ & $100.67 \pm 0.43$ & $96.1 \pm 3.84$ \\
NAP & $84.8 \pm 3.97$ & $87.31 \pm 7.06$ & $109.45 \pm 2.36$ \\
DCF & $91.25 \pm 2.65$ & $91.96 \pm 7.06$ & $86.53 \pm 1.11$ \\
& $108.01 \pm 7.54$ & $111.18 \pm 7.93$ & $103.98 \pm 8.1$
\end{tabular}

The developed method was compared with other microextraction techniques followed by HPLC-DAD analysis (Table 3). The proposed methodology had better recovery levels for KET, NAP, DCF and TCS than SBSE coated with PDMS (Silva and Nogueira 2008; Silva et al. 2008), polyurethane (PU) (Silva et al. 2008), and synthesized ionic liquids (IL) (Fan et al. 2014). BauE coated with an N-vinylpyrrolidone polymer (NVP) (Ahmad et al. 2017) gave better recoveries with the method developed here, except for CBZ with Ba $\mu \mathrm{E}$ (NVP) (Ahmad 
et al. 2017). Similar recoveries were obtained using a Ba $\mu \mathrm{E}$ coated with a synthetic polymer (P5) (Almeida et al. 2017). On comparing the amount of the sorbent phases used and their chemical properties, it was found that smaller amounts such as those reported in Ahmad et al. 2017; Almeida et al. 2017; Silva and Nogueira 2008; Silva et al. 2008), led to lower

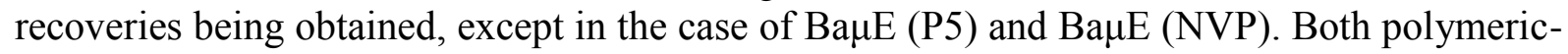
based (P5 and NVP) sorbents improved the sensitivity and selectivity of HPLC-DAD determination given that a mixed hydrophobic and $\pi-\pi$ interaction is involved in the sorption process. The LODs achieved by the developed method are almost as good both in terms of order and number as those of other microextraction techniques used in combination with HPLC-DAD (Silva et al. 2008) and they can be improved by reducing the desorption volume. Another strategy to improve sensitivity is to combine the use of a commercial PDMS rod with LC-MS/MS.

Table 3 Comparison of the LODs and average recovery of different static microextraction techniques for the determination of pharmaceuticals and triclosan

\begin{tabular}{|c|c|c|c|c|c|}
\hline Analytes & $\begin{array}{c}\text { Static micro- } \\
\text { extraction technique }\end{array}$ & $\begin{array}{c}\text { Recovery } \\
(\%)\end{array}$ & $\begin{array}{c}\text { LOD } \\
\left(\mu \mathrm{gL}^{-1}\right)\end{array}$ & $\begin{array}{l}\text { Amount } \\
\text { (g) or } \mu \mathrm{L}\end{array}$ & Ref. \\
\hline \multirow[t]{5}{*}{ NAP } & BA $\mu \mathrm{E}(\mathrm{P} 5)$ & 100.1 & 0.025 & 0.001 & (Almeida et al. 2017) \\
\hline & SBSE (IL) & 52.7 & 0.31 & $30 \mu \mathrm{L}$ & (Fan et al. 2014) \\
\hline & SBSE (PDMS) & 9.8 & 1 & 0.1201 & (Silva et al. 2008) \\
\hline & SBSE (PU) & 78.3 & 0.4 & 0.1 & (Silva et al. 2008) \\
\hline & PDMS rod & 86.53 & 0.56 & 0.037 & Present study \\
\hline \multirow{3}{*}{ KET } & BA $\mu \mathrm{E}(\mathrm{P} 5)$ & 101 & 0.05 & 0.001 & (Almeida et al. 2017) \\
\hline & SBSE (IL) & 51.6 & 0.27 & $30 \mu \mathrm{L}$ & (Fan et al. 2014) \\
\hline & PDMS rod & 96.1 & 1.02 & 0.037 & Present study \\
\hline \multirow[t]{5}{*}{ DCF } & $\mathrm{BA} \mu \mathrm{E}(\mathrm{P} 5)$ & 99.1 & 0.1 & 0.001 & (Almeida et al. 2017) \\
\hline & $\mathrm{BA \mu E}(\mathrm{NVP})$ & 87.4 & 0.02 & 0.0025 & (Ahmad et al. 2017) \\
\hline & SBSE (PDMS) & 34.6 & 1.6 & 0.1201 & (Silva et al. 2008) \\
\hline & SBSE (PU) & 77.7 & 0.7 & 0.1 & (Silva et al. 2008) \\
\hline & PDMS rod & 103.98 & 0.75 & 0.037 & Present study \\
\hline \multirow{2}{*}{ CBZ } & $\mathrm{BA \mu E}(\mathrm{NVP})$ & 102.4 & 0.02 & 0.0025 & (Ahmad et al. 2017) \\
\hline & PDMS rod & 99.07 & 3.40 & 0.037 & Present study \\
\hline \multirow[t]{3}{*}{ TCS } & SBSE (PDMS) & 78.5 & 0.1 & 0.1201 & (Silva and Nogueira, 2008) \\
\hline & $\mathrm{BA \mu E}(\mathrm{NVP})$ & 74.5 & 0.03 & 0.0025 & (Ahmad et al. 2017) \\
\hline & PDMS rod & 109.45 & 0.47 & $\mathbf{0 . 0 3 7}$ & Present study \\
\hline
\end{tabular}

The developed method was applied to the analysis of water samples from three different rivers in north-east Spain. TCS and DCF seemed to be detected although quantification was not carried out due to the poor resolution between the adjacent peaks (Fig.6 B). DCF at $\mu \mathrm{gL}^{-1}$ concentration levels have been detected in surface waters from different regions at mean concentration levels of $2.20 \mu \mathrm{gL}^{-1}$ and a maximum concentration of $18.74 \mu \mathrm{gL}^{-1}$ was found in the Llobregat river (Ginebreda et al. 2010) while in river water of South Africa was $9.69 \mu \mathrm{gL}^{-}$ ${ }^{1}$ (Madikizela and Chimuka 2017). 
The sensitive, effective and low-cost method, based on the combination of PDMS rod extraction with HPLC-DAD that has been developed here allows the determination of four pharmaceuticals (NAP, KET, CBZ, DCF) and TCS in surface water samples resulting in detection limits in the 0.47 to $1.02 \mu \mathrm{gL}^{-1}$ range, except $3.40 \mu \mathrm{gL}^{-1}$ for carbamazepine. These LODs can be improved by using a lower volume of the desorption solvent which makes this method environmentally friendly. The main advantages of PDMS rods are that they are commercial and more economical than other sorbents, and are single use, so avoiding carryover and contamination issues and allowing HPLC-DAD, which is widely available in non-specialised laboratories, to be applied for pharmaceuticals and TCS determination in surface waters.

\section{Funding}

This study was funded by the by the European Union's Horizon 2020 research and innovation program under grant agreement No 689817.

\section{References}

Ahmad SM, Ide AH, Neng NR, Nogueira JMF (2017) Application of bar adsorptive microextraction to determine trace organic micro-pollutants in environmental water matrices. Inter J Environ Anal Chem 97:484-498. doi.org/10.1080/03067319.2017.1324024

Almeida C, Ahmad SM, Nogueira JMF (2017) Bar adsorptive microextraction technique application for the determination of pharmaceuticals in real matrices. Anal Bioanal Chem 409:2093-2106. doi.org/10.1007/s00216-016-0156-y

Blair BD, Crago JP, Hedman CJ, Klaper RD (2013) Pharmaceuticals and personal care products found in the Great Lakes above concentrations of environmental concern. Chemosphere 93:2116-2123. doi.org/10.1016/j.chemosphere.2013.07.057

Bu Q, Wang B, Huang J, Deng S, Yu G (2013) Pharmaceuticals and personal care products in the aquatic environment in China: A review. J Haz Mat 262:189-21. doi.org/10.1016/j.jhazmat.2013.08.040

Cárdenas S, Lucena R (2017) Recent Advances in Extraction and Stirring Integrated Techniques. Separations 4 (1): 6. doi.org/10.3390/separations4010006

Chen M-J, Liu Y-T, Lin C-W, Ponnusamy VK, Jen J-F (2013) Rapid determination of triclosan in personal care products using new in-tube based ultrasound-assisted salt-induced liquid-liquid microextraction coupled with high performance liquid chromatographyultraviolet detection. Anal Chim Acta 767:81-87. doi.org/10.1016/j.aca.2013.01.014

Delgado A, Posada-Ureta O, Olivares M, Vallejo A, Etxebarria N (2013) Silicone rod extraction followed by liquid desorption-large volume injection-programmable temperature vaporiser-gas chromatography-mass spectrometry for trace analysis of priority organic 
pollutants in environmental

water

samples.

Talanta

117:471-482. doi.org/10.1016/j.talanta.2013.09.028

Directive 2013/39/EU of the European Parliament and of the Council of 12 August 2013. Off, in: L226 (Ed.), J. Eur. Union L226, EU Water Framework 2013/39/UE Directive, pp. 1-17.

Fan W, Mao X, He M, Chen B, Hu B (2014) Development of novel sol-gel coatings by chemically bonded ionic liquids for stir bar sorptive extraction-application for the determination of NSAIDS in real samples. Anal Bioanal Chem 406:7261-7273. doi: $10.1007 / \mathrm{s} 00216-014-8141-9$

Ginebreda A, Muñoz I, de Alda ML, Brix R, López-Doval J, Barceló D (2010) Environmental risk assessment of pharmaceuticals in rivers: Relationships between hazard indexes and aquatic macroinvertebrate diversity indexes in the Llobregat River (NE Spain). Environ Inter 36:153-162. doi.org/10.1016/j.envint.2009.10.003

Gros M, Rodríguez-Mozaz S, Barceló D (2012) Fast and comprehensive multi-residue analysis of a broad range of human and veterinary pharmaceuticals and some of their metabolites in surface and treated waters by ultra-high-performance liquid chromatography coupled to quadrupole-linear ion trap tandem mass spectrometry. J Chromatogr A 1248:104121. doi.org/10.1016/j.chroma.2012.05.084

Kasprzyk-Hordern B, Dinsdale RM, Guwy AJ (2008) The occurrence of pharmaceuticals, personal care products, endocrine disruptors and illicit drugs in surface water in South Wales, UK. Wat Res 42:3498-3518. doi.org/10.1016/j.watres.2008.04.026

He M, Chen B, Hu B (2014) Recent developments in stir bar sorptive extraction, Anal Bioanal Chem 406: 2001-2026. DOI: 10.1007/s00216-013-7395-y

Lakade SS, Borrull F, Furton KG, Kabir A, Marcé RM, Fontanals N (2016) Dynamic fabric phase sorptive extraction for a group of pharmaceuticals and personal care products from environmental waters. J. Chromatogr. A 1456:19-26. doi.org/10.1016/j.chroma.2016.05.097

Liu J-L, Wong M-H (2013) Pharmaceuticals and personal care products (PPCPs): A review on environmental contamination in China. Environ Inter 59:208-224. doi.org/10.1016/j.envint.2013.06.012

Madikizela LM, Chimuka L (2017) Occurrence of naproxen, ibuprofen, and diclofenac residues in wastewater and river water of KwaZulu-Natal Province in South Africa. Environ Monit Assess 189:348. DOI 10.1007/s10661-017-6069-1

Neng NR, Silva ARM, Nogueira JMF (2010) Adsorptive micro-extraction techniques-Novel analytical tools for trace levels of polar solutes in aqueous media. J Chromatogr A 1217:73037310. doi.org/10.1016/j.chroma.2010.09.048

Paschke A, Brümmer J, Schürmann G (2007) Silicone rod extraction of pharmaceuticals from water. Anal Bioanal Chem 387:1417-1421.doi.org/10.1007/s00216-006-0986-0

Płotka-Wasylka J, Szczepańska N, de la Guardia M, Namieśnik J (2015) Miniaturized solidphase extraction techniques. TrAC 73:19-38. DOI: 10.1016/j.trac.2015.04.026 
Popp P, Bauer C, Paschke A, Montero L (2004) Application of a polysiloxane-based extraction method combined with column liquid chromatography to determine polycyclic aromatic hydrocarbons in environmental samples. Anal Chim Acta 504:307-312. doi.org/10.1016/j.aca.2003.10.040

Prieto A, Basauri O, Rodil R, Usobiaga A, Fernández LA, Etxebarria N, Zuloaga O (2010) Stir-bar sorptive extraction: A view on method optimisation, novel applications, limitations and potential solutions. J Chromatogr A 1217:2642-2666.

doi.org/10.1016/j.chroma.2009.12.051

Richardson SD, Ternes TA (2014) Water Analysis: Emerging Contaminants and Current Issues. Anal Chem 86:2813-2848. doi.org/10.1021/ac500508t

Seethapathy S, Górecki T (2012) Applications of polydimethylsiloxane in analytical chemistry: A review. Anal Chim Acta 750 48-62. DOI: 10.1016/j.aca.2012.05.004

Silva ARM, Nogueira JMF (2008) New approach on trace analysis of triclosan in personal care products, biological environmental matrices. Talanta 74:1498-1504. doi.org/10.1016/j.talanta.2007.09.040

Silva ARM, Portugal FCM, Nogueira JMF (2008) Advances in stir bar sorptive extraction for the determination of acidic pharmaceuticals in environmental water matrices: Comparison between polyurethane and polydimethylsiloxane polymeric phases. J Chromatogr A 1209:1016. doi.org/10.1016/j.chroma.2008.08.103

Togunde OP, Cudjoe E, Oakes KD, Mirnaghi FS, Servos MR, Pawliszyn J (2012) Determination of selected pharmaceutical residues in wastewater using an automated open bed solid phase microextraction system. J Chromatogr A 1262:34-42.

doi.org/10.1016/j.chroma.2012.09.011

Valls-Cantenys C, Iglesias M, Salvadó V (2014) Two polydimethylsiloxane rod extraction methods for the sensitive determination of phenolic compounds in water samples. J Sep Sci 37:3706-3713. doi.org/10.1002/jssc.201400823

van Pinxteren M, Paschke A, Popp P (2010) Silicone rod and silicone tube sorptive extraction. J. Chromatogr A 1217(16):2589-2598. doi.org/10.1016/j.chroma.2009.11.025

Yang Y, Ok YS, Kim K-H, Kwon EE, Tsang YF (2017) Occurrences and removal of pharmaceuticals and personal care products (PPCPs) in drinking water and water/sewage treatment plants: A review. Sci Tot Enviro. 596-597:303-320.

doi.org/10.1016/j.scitotenv.2017.04.102 